Portland State University

PDXScholar

Summer 2014

\title{
Evidence-Based Decision Making in Coastal Oregon: Increasing the Effectiveness of Policy and Management Decisions
}

Kaitlin Goldsmith

Portland State University

Follow this and additional works at: https://pdxscholar.library.pdx.edu/mem_gradprojects

Part of the Environmental Indicators and Impact Assessment Commons, and the Natural Resources Management and Policy Commons Let us know how access to this document benefits you.

\section{Recommended Citation}

Goldsmith, Kaitlin, "Evidence-Based Decision Making in Coastal Oregon: Increasing the Effectiveness of Policy and Management Decisions" (2014). Master of Environmental Management Project Reports. 44. https://pdxscholar.library.pdx.edu/mem_gradprojects/44 https://doi.org/10.15760/mem.48

This Project is brought to you for free and open access. It has been accepted for inclusion in Master of Environmental Management Project Reports by an authorized administrator of PDXScholar. Please contact us if we can make this document more accessible: pdxscholar@pdx.edu. 


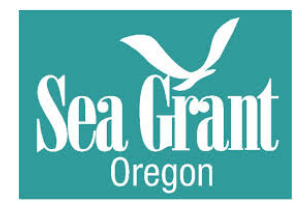

\title{
Evidence-Based Decision Making in Coastal Oregon: Increasing the Effectiveness of Policy and Management Decisions
}

\author{
Kaitlin Goldsmith
}

$8 / 4 / 2014$

Committee: Elise Granek PhD., Amy Lubitow PhD., Michael Papenfus PhD. 


\section{Chapter1: Introduction}

Scientific research provides a rigorous knowledge base that is expected to inform all levels of the decision making process (Murcia, 2009). Evidence-based decision making (National Research Council, 2012) draws on research to improve policy and management schemes (Oreszczyn and Carr, 2008). To successfully achieve environmental sustainability goals, effective decision making must incorporate the best available science into political and economic realities (Ruth et al., 2003; Roux et al., 2008). Doing so provides decision makers the tools to cope with growing uncertainties due to climatic and socio-demographic changes (Renner et al., 2013). This project seeks to foster communication between decision makers and scientists to increase evidence-based decision making. By building social capital through interactions between these two sectors, natural capital can be more effectively and efficiently utilized.

In order to infuse scientific knowledge into decision making, relevant information needs to be available, meaning research must 1 ) address specific issues and 2 ) be accessible to decision makers (Murcia, 2009). Furthermore, decision makers must be incentivized or required to base decisions on science (Murcia, 2009). To achieve this, scientists and decision makers can no longer conduct their efforts in silos (Jandl et al., 2008). This needed sciencepolicy interface engages decision makers and scientists at an early stage of developing decisions or research projects, allowing researchers to explain the knowledge they have gained, and how it may be useful in decisions (Oreszczyn and Carr, 2008). By creating this strong link, science is more likely to inform policy than by using the conventional model in which science is conducted separately from management and policymaking (Oreszczyn and Carr 2008). When decision makers and scientists come together to work through common interests, the union can achieve 
economies of scale, increase innovation, and provide the capacity to respond to pressing environmental threats (Wells and Weirner, 2007). This increase in effectiveness and efficiency of decision making practices is more likely to yield improved quality of decisions that successfully achieve society's needs (Murcia, 2009).

Yet, a disconnect in communication between sectors has prevented knowledge transfer and cooperative, interactive efforts from occurring (Murcia, 2009). This lack of communication deprives decision makers of valuable information and scientists of an understanding of pressing issues to address in research (Murcia, 2009). Generally speaking, scientists are trained to develop research projects without consulting decision makers (Murcia, 2009). Many scientists perceive that there is no political audience for their information, even if they identify decision making relevance (Stone, 2012). On the other hand, decision makers lack the time and understanding to access scientific knowledge (Murcia, 2009) and to approach scientists to generate an integrated strategy for determining research priorities (Ruth et al., 2003). A perception among decision makers that researchers' information is not relevant, and too theoretical, continues to hinder efforts to infuse scientific information into decisions (Stone, 2012). Yet, there is growing evidence that an increasing number of researchers wish to improve access of information and desire interactive engagement with decision makers (Stone, 2012). Decision makers are also concerned with effective and efficient access to research advice (Stone, 2012).

This shift has led to an increase in multidisciplinary efforts to integrate academic research into the decision making realm (Murcia, 2009). Many efforts resulting from this shift have focused on improving avenues for information dissemination. However, doing so does not 
acknowledge the extent to which users consider academic research to be relevant (Oreszczyn and Carr, 2008). Other efforts have recognized this deficiency and begun to develop research questions collaboratively between sectors and frame them to address practical issues (Murcia, 2009; Oreszczyn and Carr, 2008). There are many approaches to bridging the policy and science gap (Murcia, 2009; Oreszczyn and Carr, 2008), and the process required to translate scientific information for decision making has yet to be fully realized (Roux et al., 2008).

Here I propose a method of collaborative interaction in which research is explored and conducted with policy makers (Oreszczyn and Carr, 2008), and where both sectors carry the burden of reaching out to the other party (Murcia, 2009). This novel approach consists of two phases: 1) a diagnostic phase in which decision makers revealed their current scientific data needs regarding pressing environmental issues (Chapter 2) and 2) a collective construction phase in which decision makers and scientists were brought together to initiate the collection of policy relevant information (Chapter 3 ). In testing this method, I placed myself within the system I was researching and worked with the subjects in an interactive fashion (Oreszczyn and Carr, 2008). The benefit of this method of research is that learning can continue within the subject group after my research has ended (Oreszczyn and Carr, 2008), meaning that further cooperative efforts can continue past the initial stages of relationship development that I created. Furthermore, this research considered a diversity of perspectives by including several local level decision making entities (Cairns and Harris, 2011). This novel method also included an ecosystem services framework as a guiding principle for communication across sectors (Costanza et al., 2012; von Stackelberg, 2012). By using an ecosystem services framework in decision making, and defining environmental benefits in terms of human well-being, the 
expectation is that this will lead to more sustainable decisions and implementation of policy and management practices (von Stackelberg, 2012).

This research has focused on building connections between science and decision making sectors, by clarifying specific decision maker needs, to improve the flow of data and develop methods to address the supply side of research in decision making (Stone, 2012). The supply side dynamic focuses on improving the flow of knowledge and information to decision makers by working though barriers and opening lines of communication with scientists. A supply side analysis must address four issues causing various communication breakdowns as exhibited in the current processes of supplying scientific information to decision makers. First, I address the inadequate supply of policy relevant research (Stone, 2012) by allowing decision makers to clarify their most pressing scientific data needs. Second, the lack of access to research (Stone, 2012) is addressed through cross-sector interactions. These cross sector interactions were also conducted to address the third issue in supply side flow of data, namely poor comprehension among scientists of the policy process and how research can be relevant (Stone, 2012). Finally, the fourth issue, that researchers may be ineffective communicators (Stone, 2012), was a relevant talking point during cross-sector interactions. By approaching decision making and scientific interactions from the supply side, I have endeavored to improve communication, dissemination, and adoption of scientific information into decision making practices for a more sustainable society (Stone, 2012).

In Phase 1, I determined the key scientific data gaps of coastal and marine decision makers in Oregon. I also established what ecosystem services underlie those scientific data gaps in order to accurately address information poor policy and management schemes. 
Furthermore, I revealed that decision makers categorize ecosystem services into the pillars of sustainability (i.e., economic, social, and ecological) as compared to the traditional Millennium Ecosystem Assessment categories (2005) used by scientists. Finally, I found that the geographic location of decision makers impacted the perceived data gaps and ecosystem services priorities. Decision makers located on the coast, as opposed to inland, were more likely to balance ecological and social concerns. Understanding these findings is critical in order to improve the flow of information between the decision maker and scientific sectors, and ultimately improve upon the use of evidence-based decision making.

In Phase 2, I used the information generated during Phase 1 to develop a workshop, which I called a "synthesis session", designed to break down language barriers between decision makers and scientists for collaborative efforts to emerge. Formatting a workshop around data gaps resulted in a high level of interest among relevant decision makers and scientists. The workshop was a success in connecting sectors and increasing communication.

Based on findings from this action oriented project, this 2 phased approach can create the critical connection between sectors required to begin the process towards achieving evidence-based decision making. The connection established here can generate and transfer critical information needed to make decisions regarding policy and management schemes. Without this information, decision makers lack the ability to more effectively answer policy and management questions as they arise. While this project has focused on coastal and marine natural resource policy and management in Oregon, natural resource managers and scientists of diverse ecosystems across the nation can look to this approach as a model for establishing a critical knowledge transfer process for evidence-based decision making. 


\section{Chapter 2 (Diagnostic Phase): Information Needs Assessment for Coastal and Marine Management and Policy in the Pacific Northwest (INACaMMP): Ecosystem services under changing climatic, land use, and demographic conditions}

\section{Abstract:}

Changing climatic conditions, demographics, and land uses are projected to alter the provisioning of ecosystem services in estuarine, coastal and nearshore marine ecosystems, necessitating mitigation and adaptation policies and management. The current paradigm of siloed research efforts occurring in parallel to, rather than in collaboration with, decisionmakers will be insufficient for the rapid responses required to adapt to and mitigate for projected changing conditions in coastal areas. Here, I suggest a different paradigm: one where research begins by engaging decision-makers in the identification of priority research needs (biophysical, economic, and social), and in which researchers analyze and present data in a format most accessible to decision makers for implementing immediate changes. This paper provides insight into the varied demands for scientific research as described by decision makers on the Oregon coast by synthesizing interview data into a comprehensive portfolio of current scientific research needs and important ecosystem services. This research is an important first step in advancing efforts to develop scientific data that meet the needs of policy and decision makers working with evidence-based decision making to preserve ecosystem services.

\section{Introduction}

Limited resources, insufficient data for optimal management, and ever changing land use, demography, and climate conditions require decision makers (policy makers and managers) to 
be increasingly efficient and effective in the policy and management practices they undertake.

One approach to enhance efficiency and effectiveness of decision making is to foster collaboration between scientists and decision makers to develop pragmatic and applied research projects for evidence-based decision making (McGregor, 2006; National Research Council, 2012). Previous work has found that when decision makers are involved in the research process, scientific research is more likely to inform decisions (Wolf, 2004; Rowe \& Lee, 2012). Ultimately, more effective policy and management result from the increase of scientific data in decision making (Kerkhoff, 2005; National Research Council, 2012). Practicing evidence-based decision making to increase performance and accountability for federal agencies and NGOs is a national agenda (National Research Council, 2012).

The application of an ecosystem services framework is also a national agenda (National Science and Technology Council, 2013). Ecosystem services are defined as the benefits (goods and services) provided to humans by ecosystems (Millennium Ecosystem Assessment, 2005), and are critical to society and human life (Heal 2000). Human well-being can be enhanced or degraded by the supply and quality of ecosystem services (Millennium Ecosystem Assessment, 2005). Marine and coastal ecosystem services can be categorized as provisioning, regulating, cultural, and supporting services. Provisioning services from the ocean include food production (e.g., seafood), material production (e.g., biological material for chemical and pharmaceutical use and ornamental resources), oxygen production, and genetic resources (Zheng et al., 2009). There are several regulating services provided by the ocean, including climate regulation, waste treatment, biological control, and disturbance regulation (Zheng et al., 2009). Cultural services provided by coastal ecosystems include recreation, tribal cultural value, and scientific value 
(Zheng et al., 2009). Finally, primary production, nutrient cycling, and species diversity maintenance are supporting services provided by the marine ecosystem (Zheng et al., 2009).

The ability of the ocean to provide these services is being altered and degraded both by direct human impacts and in conjunction with the effects of climate change (Panetta et al., 2003). While $60 \%$ of ecosystem services worldwide are currently being degraded or overexploited, human demand for ecosystem services is increasing exponentially (Millennium Ecosystem Assessment, 2005; Stokstad, 2005). As human demand increases and the capacity of ecosystems to provide services degrades rapidly, sustainable management of ecosystems and their services becomes more urgent (Zheng et al., 2009).

Historically, the conservation of natural resources has focused on single sector management with a narrow set of objectives (Tallis \& Polasky, 2009). However, as ecosystems degrade and their ability to provide services declines, it has become increasingly apparent that overlooking the wide suite of ecosystem services, and applying siloed management techniques has resulted in deleterious ecosystem consequences (Tallis \& Polasky, 2009). Single-sector and single-species management fails to account for interconnections within and between ecological communities and habitats, resulting in strategies that reduce a natural systems' ability to produce a wide array of services to society (Tallis \& Polasky, 2009). An ecosystem services framework has the capacity to balance competing interests, consider ecological and economic tradeoffs of management decisions, and thereby determine best practices for natural resource management (Wainger et al., 2010). Marine management can focus on maintaining local values and benefits provided to human well-being by analyzing these tradeoffs under current and 
future climate change and land use impacted scenarios. Decision makers often lack the necessary data to consider and manage for the suite of ecosystem services.

Despite the challenges of an ecosystem services approach, incorporation of ecosystem services into management practices can make great strides in preventing further ecosystem degradation (Kareiva et al, 2011). Policymakers find that ecosystem services are a clearer means of understanding how ecosystems operate, which can result in more effective ecosystem management practices (Stokstad, 2005). By incorporating ecosystem services into policymakers' toolbox, people can begin to better manage impacts on ecosystems. Getting to this point requires making advances in the science of ecosystem services including measuring, modeling and mapping services to advise finance, policy, and governance systems (Chan et al., 2006; Daily \& Matson, 2008). Yet, there is a disconnect between what scientists and decision makers consider most pertinent to policy and governance systems.

This disconnect is exacerbated by the challenge faced by coastal and marine decision makers with a broad array of decisions concerning fisheries, species conservation, habitat protection and restoration, and spatial planning under evolving climatic and land use conditions. To effectively manage ecosystem services, decision makers require scientific data that directly addresses their data gaps (Rees et al., 2013). This method of using science-based decision making is a documented means of increasing management effectiveness in coastal ecosystems (Granek et al., 2010). The most effective means of generating relevant and usable data is by identifying a priori what information decision makers are lacking (Dobbins et al., 2007). When research is performed in direct response to decision maker needs, there is 
increased use of such information in the decision making process (Dobbins et al., 2007;

McGregor, 2006). This will ultimately enhance policies and management practices to effectively incorporate climate-related and land use impacts on coastal and marine ecosystems (Kerkhoff, 2005).

The project presented here aims to use an ecosystem services framework to identify data gaps and priority research areas that decision makers face to better manage ecosystem services. This action oriented approach provides an opportunity for scientists to then respond to scientific data needs. The ultimate goal is more effective adaptation and mitigation approaches for climate, demographic, and land use shifts. The project promotes applied research and scientific data generation addressing existing data gaps to increase the use of evidence-based policy and decision making in coastal ecosystems (Wolf 2004; National Research Council 2012).

\section{Oregon Marine Policy and Management}

In Oregon, coastal and ocean ecosystems are critically important to the state's livelihood and provisioning of natural resources (Risien, 2009). The coastal communities of Oregon, including Clatsop, Tillamook, Lincoln, Coos, and Curry counties and coastal portions of Lane and Douglas counties, are currently home to more than 210,000 people (U.S. Census Bureau, 2010), and continue to grow (Population Research Center, 2014). The combination of Oregon's growing coastal population and changing climatic conditions are increasing pressure on marine and coastal natural resources (Risien, 2009). 
New strategies are required to protect critical coastal and marine habitats from ongoing degradation. The Large Marine Ecosystem off of the US West Coast is one of the most productive regions in the world, providing a plethora of ecosystem services including commercial and recreational fishing, tourism and recreation opportunities, renewable energy, and habitat for both local and migratory species (Risien, 2009). Coastal communities and visitors identify a strong connection to spiritual and cultural benefits provided by the ocean and coast (Risien, 2009). To manage and implement ocean policy that aligns with Oregon's priorities, it is essential to identify the important, i.e., priority, ecosystem services, so that decision makers can focus on those priorities and the research community can contribute the data necessary to do so

Therefore, this project focuses on identifying the information needs of policymakers and managers working on Oregon coast issues to inform future scientific research in the state. Available and applied scientific information that addresses decision makers' information gaps can facilitate more planning that incorporates uncertainty and thus create a more resilient management scheme and ecosystem (Risien, 2009). Such resilience planning will allow decision makers to more effectively address changing climate, demographics, and land use conditions (Risien, 2009).

Oregon has a legislative commitment to utilizing scientific information, agency cooperation, and managing for a suite of coastal and marine ecosystem services. The Oregon Ocean Plan coordinated a set of policies on how ocean natural resources will be managed in Oregon (DLCD, 2014). In doing so, the Plan provides a strong legal framework for integration of state agencies, local governments, and federal agencies (DLCD, 2014). Conservation is the 
guiding principle upon which Oregon's ocean resources are managed under the Oregon Ocean Plan (DLCD, 1994). In the Plan, conservation is defined as maintaining or restoring the "integrity, diversity, stability, complexity, and productivity of marine biological communities" (DLCD, 1994, p. 2). This definition of conservation emphasizes the importance of accommodating economic development and the sustainable availability of resources into the future by minimizing waste (DLCD, 1994). The Oregon Ocean Plan expanded the decision making capacity of state agencies to move beyond historical single- species or activities to include more holistic, habitat-based approaches to ocean resource management (DLCD, 1994). This more holistic approach to ecosystem management results in more effective attainment of ocean resource goals (White et al, 2012) by protecting entire suites of ecosystem services.

With these overarching priorities in mind, the Plan requires the following legislative policies (see Table 1) to guide ocean resource management in Oregon.

Table 1: Oregon Ocean Plan policies for marine ocean resources (Adapted from Appendix G, Oregon Territorial Sea Plan, 1994).

\begin{tabular}{|l|l|}
\hline Topic of Interest & Policy \\
\hline $\begin{array}{l}\text { Marine Birds and } \\
\text { Mammals }\end{array}$ & $\begin{array}{l}\text { - Provide protection to all marine birds and mammals, especially } \\
\text { endangered, threatened and sensitive species } \\
\text { - Protect habitats which are critical to maintaining viable populations }\end{array}$ \\
\hline $\begin{array}{l}\text { Intertidal } \\
\text { Habitats and } \\
\text { Communities }\end{array}$ & $\begin{array}{l}\text { - Protect sensitive intertidal habitats and communities from pollution } \\
\text { - Protect from overuse and abuse }\end{array}$ \\
\hline Pollution & $\begin{array}{l}\text { - Emphasize pollution prevention rather than cleanup and remedial } \\
\text { measures }\end{array}$ \\
\hline Water Quality & $\begin{array}{l}\text { - Assert Oregon's leadership role in protecting marine water quality } \\
\text { - Improve state management capability through a coordinated program of } \\
\text { federal, state and local governments }\end{array}$ \\
\hline Oil and Gas & $\begin{array}{l}\text { Prohibit oil and gas exploration and development within the state } \\
\text { territorial sea }\end{array}$ \\
\hline
\end{tabular}


- Emphasize strategies to prevent oil spills from occurring in Oregon waters

These legislative policies unify various state statutes for ocean resources into one comprehensive package that includes three parts: Statewide Planning Goals, City and County Comprehensive Land Use Plans, and natural resource laws (DLCD, 2014). Thus, a coordinated effort across jurisdictional levels is mandated for the management of coastal lands and waters in Oregon (DLCD, 2014).

Oregon has 19 Statewide Planning Goals, with the last goal speaking directly to Ocean Resources. These Goals are intended to guide comprehensive land use planning through requirements passed on to the local governments and state agencies for land use decisions (DLCD, 2014). Each Goal expresses objectives for various "areas" and "habitats" in the state, with Goal 19 encompassing objectives for the state's Ocean Resources. When the Ocean Resources Management Program was initiated in 1987, Goal 19 (Table 2) became the fundamental policy element for ocean resources in land-use planning (DLCD, 1994). While Goal 17 (Table 2), for Coastal Shorelands, plays a slightly less significant role in ocean resource management than Goal 19, it is also highly relevant due to the interconnectedness of these ecosystems.

Table 2: Summary of statewide planning goals relevant to ocean resources under the Oregon Ocean Plan (Adapted from the Territorial Sea Plan, 2000).

\begin{tabular}{|l|l|}
\hline Goal & Specifications \\
\hline $\begin{array}{l}\text { Goal 19, } \\
\begin{array}{l}\text { Ocean } \\
\text { Resources }\end{array}\end{array}$ & $\begin{array}{l}\text { Establishes long term conservation and proper management of ocean } \\
\text { renewable resources as a top priority in the state. }\end{array}$ \\
$\begin{array}{l}\text { All actions by local, state, and federal agencies must strive to conserve } \\
\text { ecological functions so as to provide long term ecological, economic, and }\end{array}$ \\
\hline
\end{tabular}




\begin{tabular}{|l|l|l|}
\hline & $\begin{array}{l}\text { social values and benefits (i.e. ecosystem services) to the state. } \\
\text { - }\end{array}$ \\
\hline Goal 17, & Prioritizes living marine resources over non-renewable ocean resources. \\
\hline & $\begin{array}{l}\text { Acknowledges the importance in conserving, protecting, and restoring } \\
\text { coastal shorelines where appropriate, while also allowing for development } \\
\text { in acceptable areas. } \\
\text { - } \begin{array}{l}\text { Defines coastal shorelands as lands around coastal estuaries and streams } \\
\text { as well as } 100 \text { feet of the ocean shores. }\end{array} \\
\text { - Identifies several ecosystem services as important to protect, including } \\
\text { maintaining water quality, fish and wildlife habitat, recreational } \\
\text { opportunities, human health, and aesthetic qualities. } \\
\text { Expresses the importance of managing the shoreline in conjunction with } \\
\text { the ocean waters adjacent to it for more comprehensive protection. } \\
\text { Requires inventories of the nature, location, and extent of coastal hazards } \\
\text { and values for management and policy decisions. }\end{array}$ \\
\hline
\end{tabular}

Both Goals 17 and 19 speak to the importance of protecting a variety of ocean and coastal ecosystem services, though not necessarily using 'ecosystem services' language (Ruhl, 2007). In an effort to conserve ecological function for long-term benefits, these goals have guided ocean and coastal policy and management using an underlying ecosystem services perspective. Under the Oregon Ocean Plan, cities and counties must adhere to these goals when addressing ocean and coastal resources in their Comprehensive Land Use Plans.

City and County Comprehensive Land Use Plans are established in accordance with the Statewide Planning Goals, and comprise the second policy element of the Oregon Ocean Plan (DLCD, 2014). On the ground decisions about land use are made by local governments and state agencies, in coordination with Statewide Planning Goals (DLCD, 1994; DLCD, 2014). Hence, the day to day management of ocean resources is directly impacted by these city and county plans as they relate to the holistic and ecosystem services requirements laid out in the Statewide Planning Goals. 
Legislative statutes comprise the third policy element of the Oregon Ocean Plan (DLCD, 2014). Ocean resource threats, particularly uncontrolled development, have required Oregon Legislative action since the late 1960s In response to these threats, eight legislative natural resource statutes (Table 3) were adopted to further guide specific aspects of Oregon's ocean resources and ecosystem services in an integrated manner (DLCD, 2014).

Table 3: A brief overview of state ocean-related laws (Adapted from Territorial Sea Plan, 2000).

\begin{tabular}{|l|l|}
\hline $\begin{array}{l}\text { State ocean-related law } \\
\text { (ORS 390.605 et seq) }\end{array}$ & $\begin{array}{l}\text { Brief description } \\
\text { Declared all shore area (public or privately owned) as "state } \\
\text { use. }\end{array}$ \\
\hline $\begin{array}{l}\text { Submerged/Submersible } \\
\text { Lands (ORS 274.005 et } \\
\text { seq) }\end{array}$ & $\begin{array}{l}\text { Defined Submerged and Submersible lands and gave jurisdictional } \\
\text { authority on un-sold and otherwise publically owned parcels to the } \\
\text { state. }\end{array}$ \\
\hline $\begin{array}{l}\text { Fish and Wildlife Laws } \\
\text { (ORS 496 et seq) }\end{array}$ & $\begin{array}{l}\text { Establishes broad level policy for management of "fish" and } \\
\text { "wildlife", as defined by the law. }\end{array}$ \\
\hline $\begin{array}{l}\text { Commercial Fishing (ORS } \\
\text { 506.001-.405) \& } \\
\text { Developmental Fisheries } \\
\text { (ORS 506.450-.465) }\end{array}$ & $\begin{array}{l}\text { Establishes food-fish management policy and creates state } \\
\text { authority to regulate commercial harvest of food-fish. Establishes a } \\
\text { developmental fisheries management program to plan the } \\
\text { commercial development of underutilized food-fish species while } \\
\text { protecting long-term sustainability of the commercial and biological } \\
\text { values of those resources. }\end{array}$ \\
\hline $\begin{array}{l}\text { Kelp Leasing (ORS } \\
\text { 274.885 et seq) }\end{array}$ & $\begin{array}{l}\text { Authorizes the state to lease, with limitations on } \\
\text { area/amount/duration, lands for harvesting kelp and other } \\
\text { seaweed. }\end{array}$ \\
\hline $\begin{array}{l}\text { Threatened or } \\
\text { Endangered Wildlife } \\
\text { Species (ORS 496.172 et } \\
\text { seq) }\end{array}$ & $\begin{array}{l}\text { Requires the state to identify and establish programs to protect and } \\
\text { conserve threatened and endangered wildlife species. Provides } \\
\text { procedures and criteria for listing species. }\end{array}$ \\
\hline $\begin{array}{l}\text { Marine Water } \\
\text { Quality(ORS 468) }\end{array}$ & $\begin{array}{l}\text { Prohibits the discharge of pollutants into state waters. Provisions } \\
\text { address controlling wastes, requiring certain practices, establishing } \\
\text { effluent limitations and conditions, and setting water-quality } \\
\text { standards generally. }\end{array}$ \\
\hline $\begin{array}{l}\text { Oil Spill Contingency } \\
\text { Plans (ORS 468B.300) }\end{array}$ & $\begin{array}{l}\text { Requires an oil spill prevention and emergency response plan } \\
\text { approved prior to the operation of onshore or offshore oil or gas }\end{array}$ \\
\hline
\end{tabular}




\begin{tabular}{|l|l|}
\hline $\begin{array}{l}\text { facilities or operation of tanker, cargo, or passenger vessels in state } \\
\text { waters. }\end{array}$ \\
\hline
\end{tabular}

As previously stated, the broad and overarching goal of the Oregon Ocean Plan is to conserve the long-term values, benefits, and natural resources of the nearshore ocean and the continental shelf (Territorial Sea Plan, 2000). Hence, the provisioning of ecosystem services is important in Oregon ocean legislation. This attention to ecosystem services is made possible by the legislative framework established in the Oregon Ocean Plan (The David and Lucile Packard Foundation, 2009). The Oregon Ocean Plan (Territorial Sea Plan, 2000):

- gives higher priority to the protection of renewable marine resources than to the development of non-renewable ocean resources;

- supports environmentally sound and economically beneficial development of ocean resources for coastal communities and the state;

- protects the diversity of marine life, the functions of the marine ecosystem, the diversity of marine and estuarine habitats, and the overall health of the marine environment; and

- seeks conservation of ocean resources that are ecologically and economically of interest to the state

By establishing these 4 unifying objectives, the state is pursuing a comprehensive program for ocean resources. All local, state, and federal agencies look to these goals when making decisions about the ocean and coast to uphold the effectiveness of the Oregon Ocean Plan. Thus, it is important to work with all levels of decision makers to understand the data needs for protecting ecosystem services.

Oregon's limited resources (i.e., time, money, personnel) require added coordination and collaboration to meets multiple needs. Operating under a unified framework can facilitate this 
coordination. An ecosystem services framework can create a clear understanding of priorities under which projects can be planned in a mutually beneficial and thus efficient manner for both decision makers and scientists. Using an ecosystem services framework can enhance efforts made to increase the effectiveness of management and decision-making (National Research Council, 2012). Furthermore, while Oregon ocean planning is comprehensive at the legislative level, the existing management gaps and redundancy in marine governance in Oregon is highly inefficient (Risien, 2009). A more holistic approach to managing marine ecosystems would alleviate conflicts and increase efficiency (Risien, 2009). Thus, the opportunity to enhance on the ground use of an ecosystem services framework as a unifying force is ripe.

\section{Building on Policy-Scientific Data Frameworks}

There are two other projects in the Pacific Northwest that have endeavored to develop scientific data needs frameworks for Oregon's ocean. There is a distinctive difference in focus between these frameworks and ours. The Pacific Northwest Climate Decision Support Consortium's (PNWCIRC's) “Assessing Regional Climate Needs" project used ocean and coastal manager surveys to define climate change science needs (Lach et al., 2012). This work has taken a step back and used an ecosystem services perspective to allow decision makers to selfidentify the underlying priorities behind a much broader array of pressing scientific data needs.

Sea Grant's “West Coast Regional Research and Information Needs" assessment developed a framework of research priorities to foster collaborative work between information providers and end users through a series of workshops in Washington, Oregon, and California with stakeholders either managing, studying, or relying on ocean and coastal resources (Risien, 
2009). The Sea Grant work was focused on understanding these needs at the regional level

(Risien, 2009); the work discussed here seeks the state and local level perspectives, and thus determines if place-based knowledge differentiates scientific data needs.

\section{Methods}

\section{Data Collection}

I developed an interview process in which 19 semi-structured, roughly 1 hour interviews comprised of 12 questions were conducted with a diverse array of Oregon coastal and marine decision makers (Patton, 2002). The stakeholder interviews identified the variety of challenges facing coastal and marine decision makers, including difficulties with policy implementation and road blocks to collaboration with researchers. The semi-structured format allowed interviewees flexibility to discuss the areas of greatest concern or interest to them (Davis et al., 2013). Interviews, some which featured groups of up to 3 interviewees, were conducted between spring and fall 2013 in Salem, Portland, Corvallis, and coastal communities of Oregon. For this particular analysis, interviewees identified important ecosystem services and information gaps for addressing policy-relevant scientific needs.

Five test interviews were conducted in the spring of 2013 to verify that the questions, as posed, solicited appropriate responses and type of data sought. Interviewees selected for this process were graduate students working on applied environmental science research and resource management. Where needed, questions were altered slightly as a result of these interviews. Overall test interviews revealed that the questions yielded answers that would allow researchers to determine the data gaps and important ecosystem services in coastal policy and management practices and thus answer research questions. 
Subject recruitment was based on the criterion that each interviewee be a policy maker or manager of coastal and/or marine natural resources in Oregon. A group of six researchers, including myself and knowledgeable professionals, created a list of agencies and entities integral to Oregon's ocean and coastal resource management, including members of federal, state, and local entities and agencies, and non-governmental organizations (Table 4). Subsequently, participants were selected within each organization based on the researchers' knowledge of key decision makers in the target entities, as well as from referrals within decision making entities. Recruitment took place between June and November 2013. Ultimately, 26 decision makers participated in individual or small group interviews for this project.

Table 4: List of agencies from which decision makers were interviewed.

\begin{tabular}{|l|l|}
\hline Federal & Entities Interviewed \\
Agencies & $\begin{array}{l}\text { NOAA (Office of Ocean and Coastal Resources Management); } \\
\text { US Environmental Protection Agency; } \\
\text { US Fish and Wildlife Service; }\end{array}$ \\
\hline $\begin{array}{l}\text { State } \\
\text { Agencies }\end{array}$ & $\begin{array}{l}\text { Dept. of Environmental Quality; } \\
\text { Dept. of Fish and Wildlife; } \\
\text { Dept. of Land Conservation \& Development; } \\
\text { Dept. of Parks and Recreation; } \\
\text { Dept. of State Lands; } \\
\text { Governor's Natural Resources Office; } \\
\text { Oregon Sea Grant }\end{array}$ \\
\hline $\begin{array}{l}\text { Local } \\
\text { Entities }\end{array}$ & $\begin{array}{l}\text { City of Astoria; } \\
\text { Oregon Coastal Zone Management Association; } \\
\text { Port Orford Ocean Resource Team; } \\
\text { Tillamook Estuaries Partnership }\end{array}$ \\
\hline NGOs & $\begin{array}{l}\text { Columbia River Estuary Study Taskforce; } \\
\text { Ecotrust; } \\
\text { OR Wave Energy Trust; } \\
\text { Surfrider Foundation; } \\
\text { The Nature Conservancy; }\end{array}$ \\
\hline
\end{tabular}




\section{|l|l Tribal}

Although entities have been listed here under federal, state, local, and NGO categories (Table 4) for organizational purposes, in practice the work that several of these entities perform spans multiple categories. For example, Tillamook Estuaries Partnership reflects a local perspective of scientific data needs; however, they are also part of a nationwide circuit of NGOs called the National Estuary Projects.

Interviewees were asked to select the interview location easiest for them. The majority of interviewees chose their place of work. Thus, researchers traveled to locations across the state to obtain interview data. The majority of interviews were conducted in person; however, three interviews took place by phone. Studies directly comparing the two interview methods reveal that data obtained in person versus by phone is comparable in quality (Carr \& Worth, 2001; Novick, 2008). Prior to the interviews, participants were provided a description of the study and the process, had an opportunity to ask and have answered questions or concerns, and provided their signed consent. Consent forms informed participants that the interview was confidential and that participation could be stopped at any time.

The interview questions (Appendix A) identified and requested prioritization of current coastal management challenges and concerns to inform ongoing policy and management programs. Interview questions sought to identify policymaker and manager scientific information needs as well as important ecosystem services in policy and management practices for marine and coastal Oregon. These open ended questions (Appendix A) were designed to create a rapport between respondent and investigator, allowing respondents to communicate more freely (Carr \& Worth, 2001). 


\section{Data Analysis}

Interviews were transcribed and analyzed to establish links between the raw interview data and research objectives. After transcriptions were completed, interviewees were provided the opportunity to confirm accuracy of transcription and make minor changes to the content. Transcripts were then uploaded in Dedoose.com, an online platform for the remaining data analysis. Next, codes were developed using a general inductive approach for analyzing qualitative data to allow the investigator to develop a framework of perspectives that emerge from the raw data (Thomas, 2006). By choosing inductive analysis, this project allows the raw interview data to answer research questions without a priori expectations of results (Thomas, 2006). Consequently, a code framework emerged as the analysis progressed.

Through close reading of the raw text, I identified meaningful excerpts and created subsequent labels, or codes, thus assigning a relevant theme to a given interview response (Thomas, 2006). These emergent themes indicated the data and information needs of decision makers. The emergent themes are intended to inform future research for marine planning and identify ecosystem services considered important in a rapidly changing environment. Identifying information was removed from quotes reported here to protect participant confidentiality. Post hoc saturation analysis of codes revealed that limited codes were added after 16 interviews (Morse et al., 2014). Thus, I am confident that 19 interviews were sufficient to encompass key and primary perspectives.

Each interview was then tagged with a variety of categorizing descriptors (i.e., interviewee entity, gender, years in the field, etc.) (Appendix B). Descriptors were crossanalyzed with codes to determine if any patterns existed within the interviewee sub-groups 
(Thomas, 2006). One descriptor categorized interviewees by geographic proximity to the coast.

Classifications for this descriptor included "coastal" for those individuals working in coastal communities and "inland" for decision makers whose office was located inland. Once important ecosystem services and scientific data gaps were identified, researchers analyzed differences between coastal and inland decision maker perspectives.

\section{$\underline{\text { Results }}$}

\section{Ecosystem Services Priorities}

When asked to explain the goods, services, and benefits that the ocean provides to the community and state, interviewees identified 17 ecosystem services. These services were discussed with varying degrees of frequency. Those services discussed by a majority of interviewees included recreation, commercial fishing, economic development, and tourism (Figure 1). While decision makers were asked to reflect specifically on their ecosystem service priorities, many also reflected on ecosystem benefits, such as economic development. All ecosystem services and benefits explained to be priorities are reported here. 


\section{Ecosystem Service Priorities}

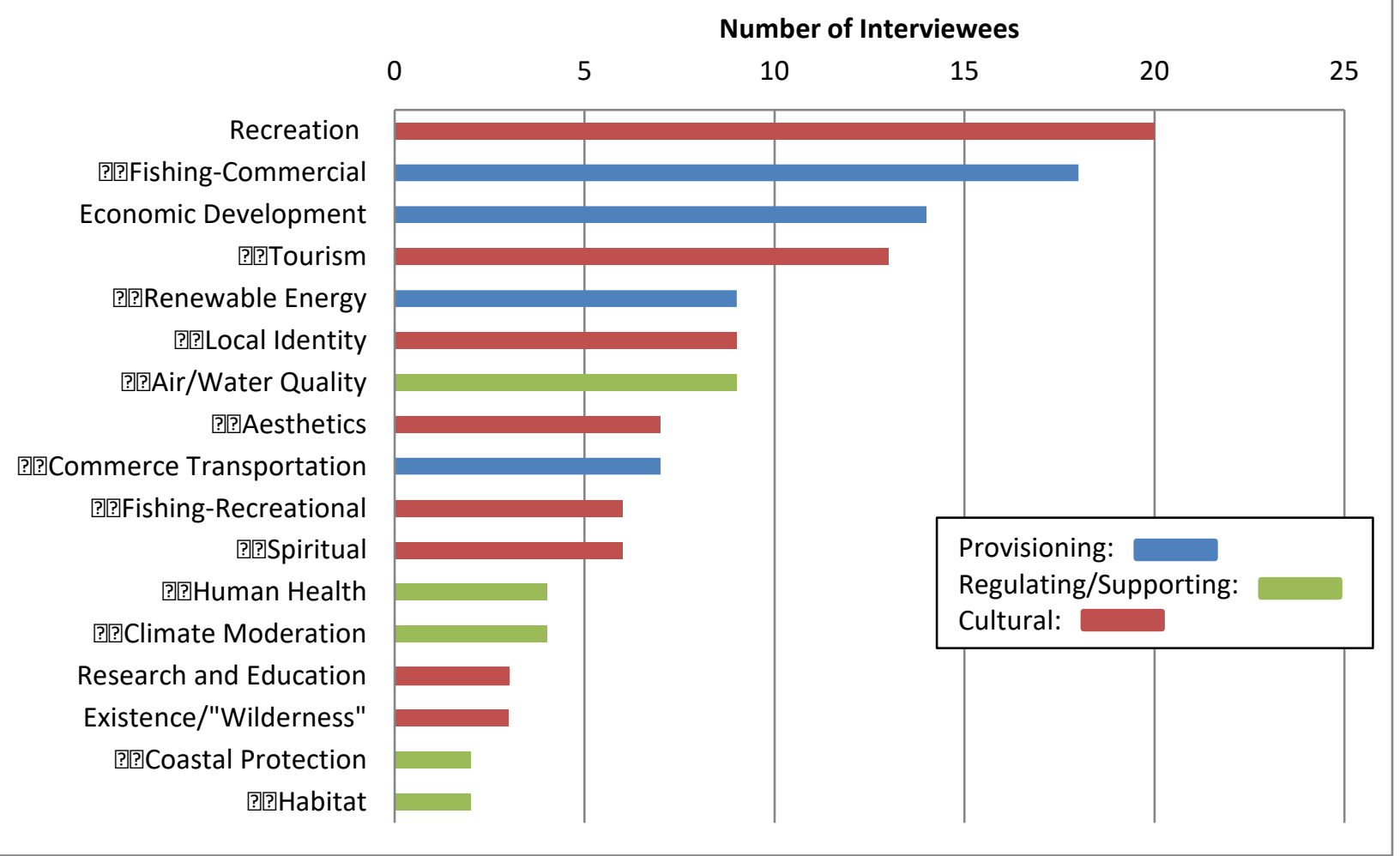

Figure 1: Overall number of interviewees whom discussed a given ecosystem services; bar color indicates category of services per MEA (2005) categorization.

In many cases, interviewees categorized their ecosystem services comments into the

pillars of sustainability (Figure 2), economic, social, and ecological (Berkes and Folke 2000); in

other cases these pillars were implied. While researchers of ecosystem services often

categorize services into the Millennium Assessment's (2005) ecosystem services categories of

supporting, provisioning, regulating, and cultural (Figure 1), exclusively doing so here would

misrepresent part of the decision makers' perspectives. While the interview question asked

interviewees to identify ecosystem services (Appendix A), many decision makers also discussed

benefits generated by those ecosystem services (Haines-Young \& Potschin, 2010). 


\section{Ecosystem Services by Pillars of Sustainability}

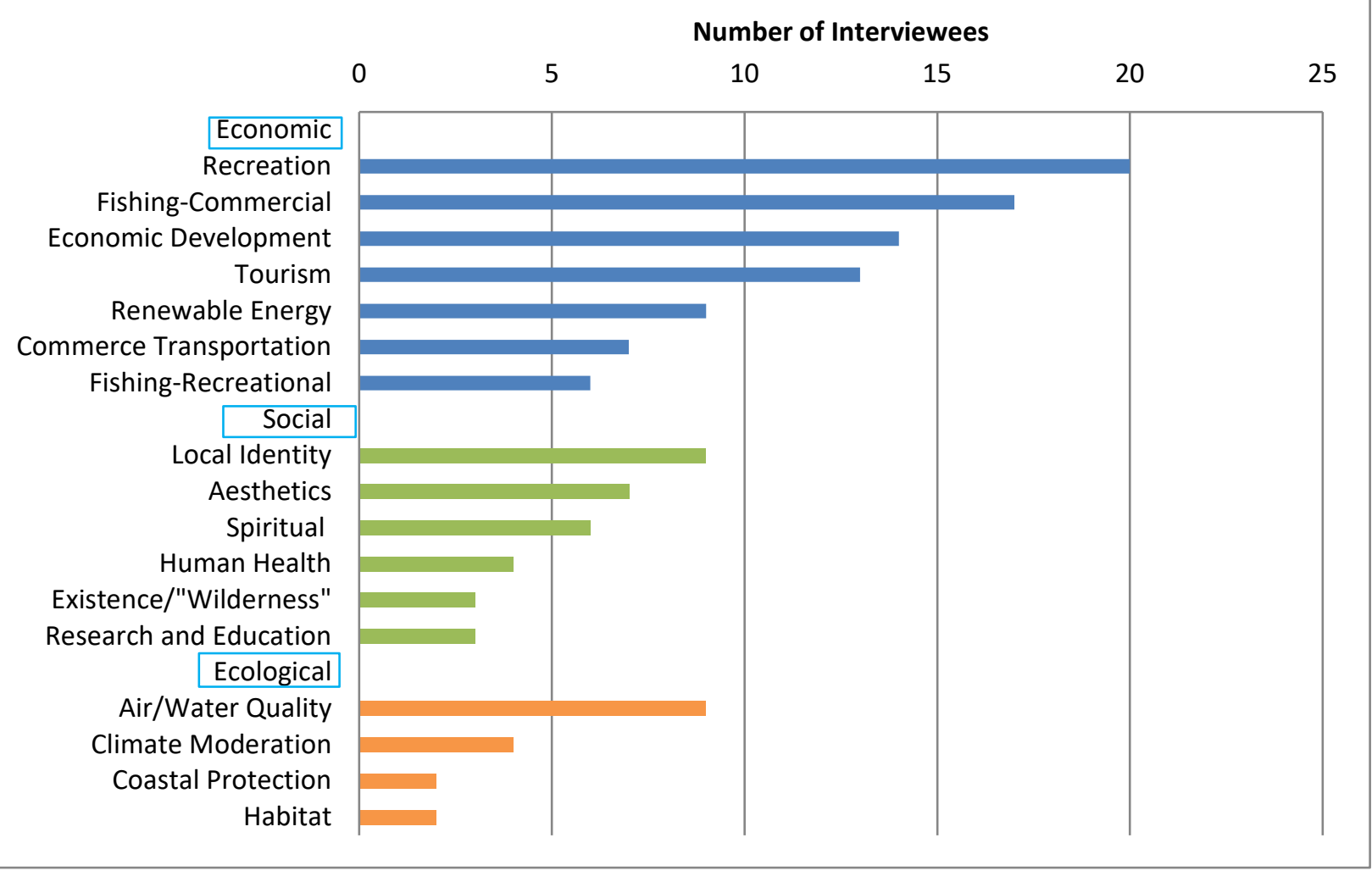

Figure 2: Number of interviewees whom discussed a given ecosystem service, categorized by pillars of sustainability.

I grouped the services identified by sustainability categories. The economic category

included eight subordinate services/benefits discussed: recreation, commercial fishing,

recreational fishing, economic development, renewable energy, tourism, and commercial

transportation (Figure 2). Services contributing to social sustainability included a sense of local

identity, aesthetics, spirituality, human health, existence of a "wilderness" seascape, and

coastal based research and education (Figure 2). Services of ecological relevance included air

and water quality, climate moderation, coastal protection, and habitat (Figure 2). 


\section{Ecosystem Services for Economic Sustainability}

The array and frequency with which ecosystem services supporting economic sustainability were mentioned outweighed mention of both social and ecological ecosystem services combined. The interviewees discussed the many benefits the coast and ocean provide to Oregon's economy, including local jobs provided by this economic engine. While inland decision makers defined this economic engine as a statewide benefit, their coastal counterparts focused on the community benefits provided. For example, one decision maker located inland explained: "I think in general terms the coast is a tremendous asset to the state economically", while a coastal decision maker explained the economic value of coastal ecosystem services as: "That whole spectrum of the marine economy... [that] the ocean provides for the people that live on the coast here".

When discussing economically beneficial ecosystem services (Fig. 2), many interviewees discussed recreational activities. Frequently decision makers acknowledged the close tie between recreation and tourism in the state, rationalizing that people who recreate will often also eat or shop on the coast.

Another prioritized economic sustainability-related ecosystem service, according to decision makers, was tourism. Tourism was explained as an asset to the coastal community by decision makers who were located inland from the coast. One inland interviewee describes that: "The lifeblood of those communities economically is tourism". Coastal decision makers discussed tourism benefits as a draw that brought people to their communities or "tourist town[s]". Overall, decision makers who discussed tourism explained it to be a critically 
important good or service that results in money being brought to and exchanged in coastal Oregon.

It was explained that fisheries in Oregon waters have an important connection to the economy of the state. As one decision maker states: "We have a high recognition of the value of the marine economy, whether it's commercial fishing or recreation fishing". While recreational fisheries were discussed by many interviewees, commercial fisheries were more frequently discussed as an ecosystem service. Decision makers located in coastal communities discussed commercial fisheries as having an element of local identity attached to them. One interviewee noted: "This is a fishing community, and so the whole fishing industry and how that's impacted by various uses [is important]".

While renewable energy was not brought up as frequently as other ecosystem services, there was a difference in perception of its status between inland and coastal based decision makers. If a decision maker was located geographically inland from the coast, they often expressed renewable energy as an emerging ecosystem service provided by the ocean, discussing its development and identifying areas for its production. By contrast, coastally located interviewees were more apt to discuss renewable energy as a potential ecosystem service and tended to convey a general apprehension when discussing renewable energy by using terms like "possibly" or "potential" and "to be determined".

\section{Ecosystem Services for Social Sustainability}

Important ecosystem services that contribute to social sustainability were brought up by interviewees second most often. This category includes local identity and aesthetics as most 
frequently discussed, but both of these were discussed by less than $1 / 2$ of interviewees (Figure 2).

Notions of deep seeded spirituality and "connection" to the vast and expansive sea were found within this category. Interviewees conveyed a significant importance when speaking of these goods and services. One interviewee portrayed this when they stated: "You cannot overstate the centrality of the ocean".

Local identity was the sense of a cultural tie to the ocean not possessed by inland areas. According to interviewees, having the ocean imparts a particular character on the state of Oregon and its people. As with other ecosystem services, the local identity service differed between coastal and inland decision makers. Inland based decision makers referenced a connection to the "people" and "the community" when explaining local identity. By contrast, coastal based decision makers used "we" and expressed a clear sense of ownership. Put bluntly by one coastal interviewee: "It defines who we are". Thus, while both geographically inland and coastal decision makers discussed local identity as a service the ocean provides, the level of intimacy differed.

According to interviewees, the aesthetics of the Oregon coast provide enjoyment to people both living on and visiting the coast, and was thus expressed as another important ecosystem service. Furthermore, aesthetics are clearly seen as something that draws people to either live on or visit the coast. "People come to the Oregon coast for its natural beauty". So while this service supports social sustainability, there is a sense that it spurs the economic benefit of tourism as well. While coastal and inland based decision makers both had the same 
perspective regarding aesthetics, coastal decision makers were over twice as likely to mention aesthetics as an ecosystem service than their inland counterparts.

Similar to aesthetics, coastal decision makers were twice as likely to discuss the spiritual benefit of the ocean, though, both had the same perspective on what this spiritual connection was. Sentiments regarding the comforting renewal provided by the coast were commonly expressed.

Maintaining human health was offered as another important social sustainability related ecosystem service. Interviewees explained that human health related to a clean and safe environment, in which people could use and extract goods without fear of repercussions to their health. Human health was a rare case in which no coastal decision makers discussed this benefit.

\section{Ecosystem Services for Ecological Sustainability}

Services that support ecological sustainability include benefits people may or may not realize they are gaining from the ocean's functions. For example, many interviewees discussed that ocean functions and processes that extract impurities from the air result in oxygen benefits to the people in the state; and yet, as one interviewee explained: "[The public] might derive some ecosystem benefit from [the ocean], like clean water...but the ocean,...it's just there".

One might speculate that it is for this reason that of the 3 categories, ecosystem services supporting ecological sustainability were the least discussed by interviewees. For these 
ecosystem services there was the least difference between coastal versus inland decision makers' perceptions.

According to decision makers, the maintenance of air and water quality was most significant among ecological sustainability-related services. Interviewees defined this as a "true asset", but found that it was overall "undervalued" and much less obvious than the extractive benefits of the ocean. While some individuals talked about air quality and water quality directly, others used the subsequent benefits provided, i.e., clean water and oxygen. Though there was this perception among some interviewees that the Oregon ocean provides clean water, it is unclear from where this perspective originates and to what ecosystem function it speaks.

Interviewees also noted that climate moderation was an ecosystem service provided by the coast. Particularly, this service was explained as the regulation of cycles and climate patterns. This was important due to its stabilizing features.

\section{$\underline{\text { Scientific Data Needs }}$}

After explaining their ecosystem service priorities, decision makers were asked to reflect on important scientific data gaps in their current policy and management efforts. Interviewees brought up 19 types of scientific information they considered pertinent to present coastal policy and management needs (Figure 3). These needs ranged from rather broad, such as water quality data and ecosystem services data, to more specific, including littoral cell studies and updated information for the Estuaries Plan Book. While all data needs are important to address 
for the purpose of data-driven decision making, 6 of these needs were discussed by a majority of interviewees (Figure 3).

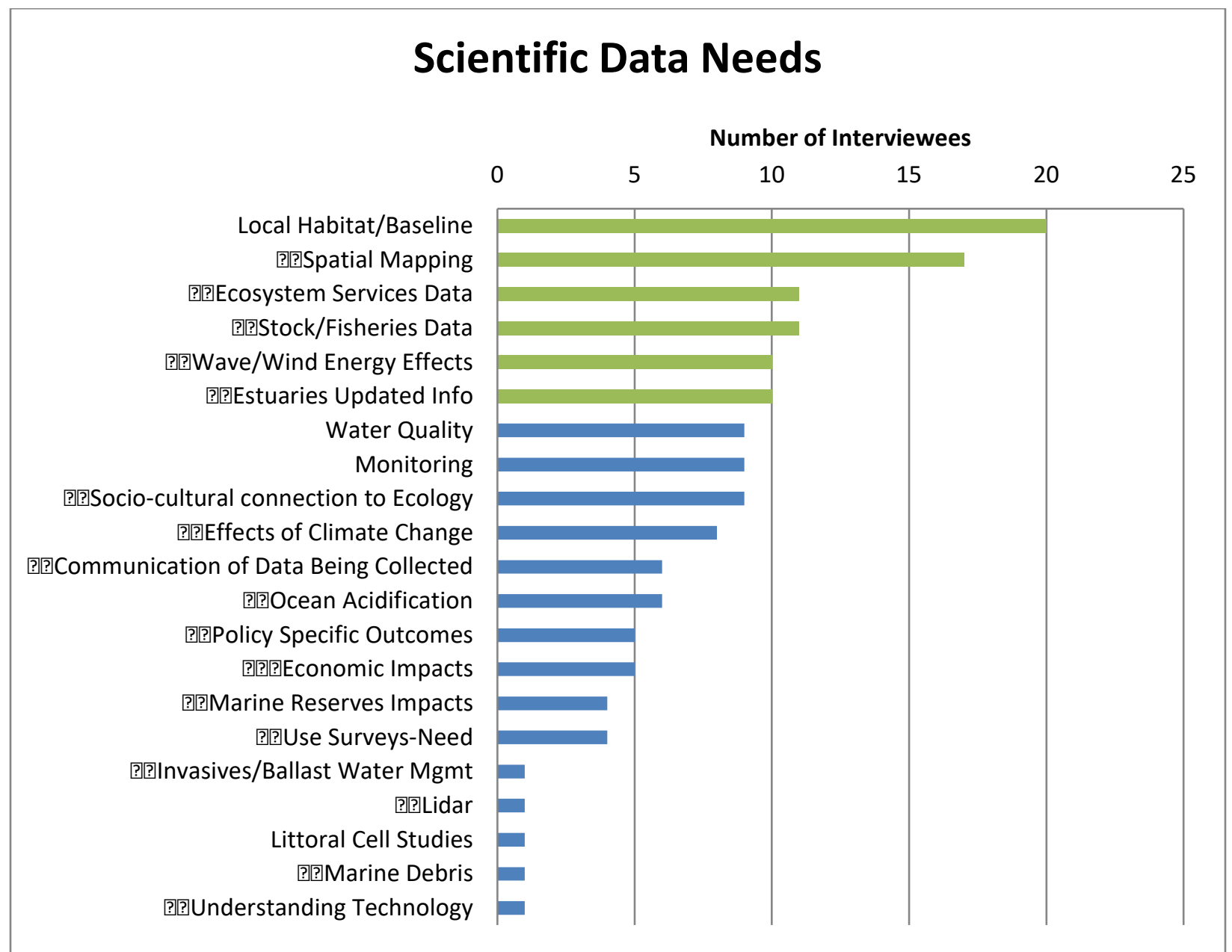

Figure 3: Frequency of all scientific data needs discussed by decision makers interviewed, with the 6 most common needs emphasized in green.

\section{Local Habitat/Baseline Need}

The local habitat and baseline data need includes several sub-data needs. Interviewees identified scientific data to answer the questions "what's out there", "where are things [located]", "what areas are [species] using", "how does this [eco]system work", "what are the current conditions" and "ocean processing" as important data gaps. There is a perceived need to answer various questions about the local species composition and ecosystem functions, and 
interviewees stated this need to be important for a number of applications. They expressed the need to catalog and inventory this information at the local level for use in understanding what areas need to be managed, how to manage them, and to measure the outcomes of management decisions. Interviewees also stated that a critical use of these data would be for localized climate change adaptation and mitigation strategies, noting that baseline information is important to understand where and how climate change issues are impacting coastal communities. According to interviewees, employing these data to then convince the general public of the value and need for various management decisions and practices would be useful. While sentiments expressed by both coastal and inland interviewees were very similar, the coastal individuals discussed the need for localized baseline and habitat information about $67 \%$ more often than inland decision makers.

\section{Spatial Mapping Need}

The next most frequently discussed scientific data need was high resolution spatially mapped data. When interviewees discussed the need for spatially explicit data, they were speaking about two types of spatial data 1) visual representation of the ecosystem and ecological community information about species, their habitats, and their movements and 2) identification of various uses in the ocean, including existing competing uses, emerging uses, and how these uses overlap currently and in the future. As one interviewee explained, this information is important "so that when decisions are made...there is an understanding of who is being impacted or who may benefit". Overall, decision makers who discussed this data need 
expressed that the information plays a critical role in comprehensive ocean planning and identification of who will benefit/be impacted by decisions.

\section{Ecosystem Services Data Need}

According to interviewees, more research on ecosystem services is needed. This type of information was perceived as desirable overwhelmingly more often by coastal relative to inland decision makers, with a ratio of nearly $3: 1$. While decision makers also discussed some ecosystem services data needs (i.e., stock/ fisheries data, effects of marine renewable energy), this category seemed to be a catch-all for supporting and regulating services data needs. Some interviewees felt that more information regarding ecosystem services was key for communicating to the public the worth of management practices on the coast, particularly in dollars spent on restoration projects. In this vein, one interviewee cautioned that using ecosystem services to communicate natural resource issues to the public can be cumbersome as the concept is "difficult thing for people to get their mind around". Thus, the need for more ecosystem services research is tied to further developing a "definition and description" of these services as well as methods for how "they are to be measured". Creating more concrete measurement strategies can facilitate better communication of the importance of coastal and marine ecosystems.

\section{Stock/Fisheries Data Need}

Coastal and inland decision makers alike commented on the need for stock and fisheries data with about the same frequency and in the same context. Oregon's fisheries are "data poor" according to one interviewee. The kinds of information interviewees found necessary 
included information on life history characteristics, "genetic differences", "range shifts", and distribution, as well as fisheries production, population, and abundance. The stock assessments information need also included understanding oceanographic processes that affect fish populations and habitats. One interviewee noted that this type of information should be gathered from ecological fieldwork as well as from primary users of the fisheries, i.e., commercial fisherman. Decision makers found this information critical in defining the scale of a fishery stock, and also in defining catch limits in order to maintain a "sustainable yield" from the fisheries.

\section{Wave/Wind Energy Effects Need}

As an emerging use in Oregon's ocean, many interviewees recognized the need to understand the impacts of marine renewable energy, i.e., wind and wave energy. There was concern among interviewees that marine renewables may adversely impact the environment, and thus research must be conducted to avoid these impacts. Potential adverse impacts that warrant research include impacts of acoustics, electro-magnetic forces, benthic habitat disruptions, sediment transport resulting from the presence of renewable devices, impacts to sea mammals and birds, and, to a lesser degree, toxicology of renewable devices. Additionally, in order to improve upon marine spatial planning in the state, a need was expressed "to develop a robust understanding with the science and the community in a holistic, synergistic, multidisciplinary approach" of sites at high potential of adverse impacts from renewable energy. Also suggested was the need to understand the effect of marine renewable energy on the visual resources of the coastline. Another scientific data need regarding marine renewable 
energy involved enhancing the technologies themselves. Many interviewees explained that the technology to generate energy from marine renewables is still limited, and that there is a need to conduct further research to improve upon this. Decision makers found these information needs for both ecological impacts and technological improvements important for developing regulations regarding marine renewables and for permitting purposes.

\section{Updated Estuaries Information Need}

The expressed need for estuaries information seemed to stem from current efforts to update the state's Estuary Plan Book, which identifies plans for all major and minor estuaries along the Oregon coast. Information in the current Estuary Plan Book was collected in the 1970s and 1980s, thus estuary plans are based on information that is several decades old (Andy Lanier pers. comm.). Compiling these scientific data would allow decision makers to better understand the various forces influencing estuarine habitat and ecosystem services. According to one interviewee, "the [Statewide Planning Goals] themselves are pretty solid... [but] the information they're based on dictates the outcome", meaning that effective on the ground implementation of the Estuary Plan Book is highly dependent on the scientific information available. As one interviewee further divulged, "we would probably do a better job if we had better, more precise, more site specific, updated information". Gathering updated information on estuaries would also benefit monitoring efforts. With additional baseline data, decision makers may be able to better predict or project potential consequences of regulations that otherwise would be unforeseen. Other benefits of obtaining updated information about estuaries include the ability to improve water quality standards and understand the carbon 
sequestration potential of these ecosystems. Impacts on estuaries, including sea level rise, fishing management, and ocean acidification, can be better managed with this information. One decision maker notes, "our estuaries are key in so many of these...issues that we need to address".

\section{$\underline{\text { Discussion }}$}

This work sought to engage stakeholders in defining their ecosystem services priorities and scientific data needs in order to generate responsive action from the scientific community to provide or generate appropriate data. Doing so will infuse more scientific data into the marine and coastal management and policy practices (Dobbins et al. 2007). Understanding ecosystem data needs in conjunction with ecosystem services priorities allows scientific research to be conducted in a more applied and holistic manner, thus saving both sectors time and money.

This project acts as a knowledge broker between decision makers and scientists in the first step to achieving evidence-based policymaking (Choi et al. 2005). Interviews with decision makers of coastal and marine natural resources revealed focal areas for future scientific data collection as well as the framing of ecosystem services to address pillars of sustainability. The process revealed that diverse priorities and perspectives of ecosystem services are a driving force behind identified data needs. Finally, geographic perspectives, resulting from proximity to the coast, were similarly reflected in data needs.

The manner in which ecosystem service data needs are categorized is an important perspective to consider when understanding decision makers' data needs. While the traditional Millennium Ecosystem Assessment categories for ecosystem services include supporting, 
regulating, provisioning, and cultural (2005), interviewees both implicitly and explicitly categorized their ecosystem services priorities into the pillars of sustainability categories, namely economic, social, or ecological benefits. This likely reflects the close connection that decision makers have with the public, as research indicates a public distrust of the ecosystem services framework (Metz, 2013). As one interviewee explained: "sometimes [ecosystem services] becomes a barrier...When you actually start talking in plain terms about what the service is, [the public] has a better feel for it and understand it". This preference to categorize ecosystem services into the pillars of sustainability is important to understand in order to more effectively communicate across sectors and incorporate these services into holistic management of ecosystems. By managing for ecosystem services, human values and well-being can be sustained and enhanced while minimizing negative impacts to the long term provision of these benefits (Zheng et al. 2009).

The findings of this assessment reveal that ecosystem services expressed as management priorities closely aligned with the identified scientific data needs. This link can be demonstrated by the top ecosystem services and scientific data needs expressed by the majority of interviewees (Table 5): 1) The ecosystem service priority for recreation leads to the need for scientific data such as spatial mapping of uses, ecosystem services data, local habitat information, and to some extent estuaries information 2) The ecosystem service of commercial fisheries is directly associated with the need for stock and fisheries data, as well as local habitat and baseline data, and spatial mapping 3) Attempts to protect the ecosystem services benefit of economic development in management and policy will require information about the effects of renewable energy and spatial mapping of marine economic industries 5) Managing the 
ecosystem service of tourism requires ecosystem services data, local habitat data, and spatially mapped uses.

Table 5: Ecosystem services and scientific data needs that were expressed most frequently.

\begin{tabular}{|c|c|}
\hline Ecosystem Services & Scientific Data Needs \\
\hline 1. Recreation & 1. Local Habitat, Baseline Data \\
\hline 2. Commercial Fisheries & 2. Spatial Mapping \\
\hline 3. Economic Development & 3. Ecosystem Services Data \\
\hline \multirow[t]{3}{*}{ 4. Tourism } & 4. Stock, Fisheries Data \\
\hline & 5. Effects of Renewable Energy \\
\hline & 6. Updated Information on Estuaries \\
\hline
\end{tabular}

An awareness of these perspectives allows scientists to develop research projects understanding the type and format of data that will be most useful and of highest priority in decision making. For example, both this study and the similar study conducted by the PNWCIRC found that managers are looking for more spatially explicit data that can be visualized in maps. However, the difference in underlying priorities used to develop the scientific data frameworks by PNWCIRC and here resulted in different kinds of spatial mapping data needs. PNWCIRC's framework focuses on the need for spatial mapping regarding temperature and water variability (Lach et al., 2012), while our research revealed a need for spatially mapped data relating to commercial fisheries and recreation activities. Thus, different scientific research data can emerge to respond to a need for spatially mapped data depending on the underlying priority. If decision makers are encouraged to define these priorities up front, then responsive scientific research can more aptly answer the true questions being asked in coastal and marine policy and management. 
This categorizing of ecosystem services into the sustainability pillar perspective is likely the reason why economic development was expressed as a service despite it being a benefit provided by ecosystem services. Economic development has a direct and undeniable link to economic sustainability. Thus, decision makers were compelled to declare economic development as a priorities ecosystem service.

Additionally, in this research, the socio-cultural experiences of decision makers influenced their ecosystem service priorities and thus data needs for marine and coastal resources. This understanding of ecosystem services priorities can assist researchers in identifying potential research projects that fulfill multi-sector needs and thus increase efficient use of limited resources. The Sea Grant "West Coast Regional Research and Information Needs" project explains that new and emerging ocean uses give rise to a need for place-based scientific information (Risien, 2009). In our work, there emerged a clear need to reveal place-based priorities that underlie scientific data needs.

For example, both Sea Grant's project and ours found that baseline information is needed to address marine and coastal natural resources management (Risien, 2009). Yet, the type of baseline information needed varied: this project identified a need for local habitat structure and function information that is place-based and interconnected; while the Sea Grant project emphasized a need to understand the Pacific regional marine ecosystem (Risien, 2009). These variances reflect the scope difference of the two projects. By discussing local priorities and scientific data needs, this project has revealed the significant influence geography can play in studies of decision maker data needs (Cantrill \& Senecah, 2001). 
Research has shown that a person's sense of place and their immediate surroundings impacts their perspective about the local environment and collective views among a group of people will be crafted by their in situ view of their immediate surroundings (Cantrill \& Senecah, 2001; Cheng \& Daniels, 2003). This results in differing understandings of natural space between local and non-local people (Gareau, 2007). This sense of "home" for local people emerges in how they frame the environment under policy and management practice (Cantrill \& Senecah, 2001). In this project, this divergence of perspective emerged when comparing the scientific data needs and underlying ecosystem service priorities of coastal based versus inland based decision makers. Actions taken regarding marine resource management will mirror one's selfidentity and proximity to the resources (Cheng et al., 2003). Because local stakeholders see their surroundings in an ecological and sociocultural way (Gareau, 2007), they are more inclined to balance conservation needs with social demands. The fact that coastal based decision makers expressed economic development as an ecosystem priority twice as often as their inland based colleagues is one piece of evidentiary support that differing perspectives based on geographies exists in marine and coastal decision makers. Given this dynamic, comprehensive marine and coastal resource management should include this variability of perspective when endeavoring to understand important ecosystem services and scientific data needs (Davis et al., 2013). Having both local and non-local decision maker perspectives will result in management schemes that are more effective and legitimized at the local level (Gareau, 2007).

Here I have developed and applied one means of starting the process to connect decision makers with scientific researchers to address pressing marine and coastal resource concerns in ocean communities and states. After defining these needs, the next step is for scientific 
researchers and funding agencies to identify decision makers with whom they can work to develop applied and responsive research projects addressing these needs and/or to communicate research that fulfills these needs.

\section{References}

Population Research Center. (2014). Annual Oregon Population Report. Portland State University: College of Urban \& Public Affairs.

Berkes, F., \& Folke, C. (2000).Linking social and ecological systems: Management practices and social mechanisms for building resilience. New York, NY: Cambridge University Press.

Carr, E., \& Worth, A. (2001). The use of the telephone interview for research. Nursing Times Research, 6 (511), 511-524. doi: 10.1177/136140960100600107

Cantrill, J. \& Senecah, S. (2001). Using the 'sense of self-in-place' construct in the context of environmental policy-making and landscape planning. Environmental Science \& Policy, 4, 185-203.

Chan K, Shaw M, Cameron D, Underwood E, Daily G. (2006). Conservation Planning for Ecosystem Services. PLoS Biology 4(11): 2138-2152.

Cheng, A. \& Daniels, S. (2003). Examining the interaction between geographic scale and ways of knowing in ecosystem management: A case study of place-based collaborative planning. Forest Science, 49(6), 841-854.

Cheng, A., Kruger, L., Daniels, S. (2003). "Place" as an integrating concept in natural resources politics: Propositions for a social science research agenda. Society and Natural Resources, 16, 87-104.

Choi BCK, Pang T, Lin V, Puska P, Sherman G, et al. (2005). Can scientists and policymakers work together? J Epidemiol Community Health. 59:632-637.

Daily G, Matson P. (2008). Ecosystem Services: from Theory to Implementation. Proceedings of the National Academy of Sciences 105(28): 9455-9456.

Davis, E., Moseley, C., Olsen, C., Abrams, J., Creighton, J. (2013). Diversity and dynamism of fire science and user needs. Journal of Forestry, 111(2), 101-107.

Dobbins M, Rosenbaum P, Plews N, Law M, Fysh A. (2007). Information transfer: what do decision makers want and need from researchers? Implementation Science. 2(20): 1-12. 
The David and Lucile Packard Foundation. (2009). Synthesis report for the ecosystem-based management for sustainable coastal-marine systems initiative. Retrieved from http://www.packard.org/wp-content/uploads/2011/03/Synthesis-Report-for-the-EBMInitiative.pdf

Executive Order of the President of the United States (EOP). (2009). Interim Framework for Effective Coastal and Marine Spatial Planning. Interagency Ocean Policy Task Force; The White House Council on Environmental Quality.

Granek, E.F., Polasky, S., Kappel, C.V., Reed, D.J., Stoms, D. M., Koch, E. W., Kennedy, C. J., Wolanski, E. ( 2010). Ecosystem Services as a Common Language for Coastal EcosystemBased Management. Conservation Biology, 24, 1, 207-216.

Gareau, B. (2007). Ecological values amid local interests: Natural resource conservation, social differentiation, and human survival in Honduras. Rural sociology, 72(2), 244-268.

Haines-Young R \& Potschin M. (2011). Common International Classification of Ecosystem Services (CICES): 2011 Update. Centre for Environmental Management, University of Nottingham , UK.

Heal G. (2000). Valuing Ecosystem Services. Ecosystems 3(1): 24-30.

Kareiva P, Tallis H, Ricketts T, Daily G, Polasky S. (2011). Natural Capital: Theory and Practice of Mapping Ecosystem Services. Progress in Physical Geography 35(5): 701-704.

Kerkhoff L. (2005). Integrated Research: Concepts of Connections in Environmental Science and Policy. Environmental Science and Policy 8 (2005): 452-463.

Lach D, Parker A, Boesl M. (2012). Assessing Regional Climate Needs. Pacific Northwest Climate Decision Support Consortium.

McGregor M. (2006). What decision-makers want and what they have been getting. International Society for Pharmacoeconomics and Outcomes Research. 9(3): 181-185.

Metz D. (2013). The language of conservation 2013: Updated recommendations on how to communicate effectively to build support for conservation. Public Opinion Strategies. Fairbanks, Maslin, Maullin, Metz \& Associates.

Millennium Ecosystem Assessment. (2005). Ecosystems and Human Well-Being: Synthesis. Washington, D.C.: Island Press. 
Morse WC, Lowery DR, Steury T. (2014). Exploring saturation of themes and spatial locations in qualitative public participation geographic information systems research. Society \& Natural Resources: An international journal. 27 (5): 557-571.

National Research Council. (2012). Using Science as Evidence in Public Policy. Committee on the Use of Social Science Knowledge in Public Policy, K. Prewitt, T.A. Schwandt, and M.L. Straf, Editors. Division of Behavioral and Social Sciences and Education. Washington, DC: The National Academies Press.

National Science and Technology Council, Subcommittee on Ocean Science and Technology (2013). Science for an ocean nation: Update of the ocean research priorities plan. Washington, D.C. 20502.

Novick, G. (2008). Is there a bias against telephone interviews in qualitative research? Research in Nursing and Health, 31, 391-398.

Oregon Department of Land Conservation and Development (DLCD). (n.d.). Institutional setting. Retrieved from http://www.oregon.gov/LCD/OCMP/pages/ocean_inst.aspx

Oregon Department of Land Conservation and Development (DLCD). (n.d.). Ocean resources. Retrieved from http://www.oregon.gov/LCD/OCMP/pages/ocean_intro.aspx

Oregon Department of Land Conservation and Development (DLCD). (n.d.). Oregon Coastal Program Overview. Retrieved from http://www.oregon.gov/LCD/OCMP/pages/ocmp_intro.aspx

Oregon Department of Land Conservation and Development (DLCD). (n.d.). Oregon's Ocean Resources Management Plan. Retrieved from http://www.oregon.gov/LCD/OCMP/Pages/Ocean_Plan.aspx

Oregon Department of Land Conservation and Development (DLCD). (2010). Oregon's statewide planning goals \& guidelines; goals 19: Ocean resources (OAR 660-0150010(4)). Retrieved from website: http://www.oregon.gov/LCD/docs/goals/goal19.pdf

Oregon Department of Land Conservation and Development (DLCD). (n.d.). Principle Policies of the Oregon ORMP. Retrieved from http://www.oregon.gov/LCD/OCMP/Pages/Ocean_Policies.aspx

The Oregon Ocean Resources Management Task Force. (1991). Oregon's Ocean Resources Management Plan: Getting the Job Done. Retrieved from http://www.oregon.gov/LCD/OCMP/docs/ocean/op5process.pdf 
Panetta LE, Adams JH, Claussen E, Guerrero CL, Hayden M, Heal G, Kennel CF, Knowles T, Lubchenco J, Packard J, Parravano P, Pataki GE, Riley JP Jr., Rockerfeller D JR., Rufe RT Jr., Sullivan KD, Ware M, White PD. (2003). America's Living Oceans: Charting a Course for Sea Change (A Report to the Nation). PEW Oceans Commission.

Patton, M. Q. (2002). Qualitative research and evaluation methods. Thousand Oaks, Calif: Sage Publications.

Rees SE, Austen MC, Attrill MJ, \& Rodwell LD. (2013). Incorporating Indirect Ecosystem Services into Marine Protected Area Planning and Management. International Journal of Biodiversity Science, Ecosystem Services \& Management. 8(3): 273-285.

Risien, J. (ed.). (2009). West Coast Regional Marine Research and Information Needs. Oregon Sea Grant. ORESU-Q-09-001. Corvallis, OR.

Rowe, A. \& Lee, KN. (2012). Linking knowledge with action: And approach to philanthropic funding of science for conservation. A report to the Conservation \& Science Program, David \& Lucile Packard Foundation.

Ruhl, J. B., Kraft, S. E., \& Lant, C. L. (2007). The law and policy of ecosystem services. Washington: Island Press.

Stokstad. (2005). Taking the Pulse of Earth's Life-Support Systems. Science 308 (5718): 41-43.

Tallis, H., \& Polasky, S. (2009). Mapping and Valuing Ecosystem Services as an Approach for Conservation and Natural-Resource Management. Annals of the New York Academy of Sciences, 1162(01), 265-283.

The Territorial Sea Plan. (2001). http://www.oregon.gov/LCD/OCMP/Pages/Ocean_TSP.aspx

Thomas, D. (2006). A general inductive approach for analyzing qualitative evaluation data. American Journal of Evaluation, 27(237), 237-246. doi: $10.1177 / 1098214005283748$

U.S. Census Bureau. (2010). 2010 Census: 2010 Demographic Profile. http://www.census.gov/popfinder/

Wainger LA, King DM, Mack RN, Price EW, \& Maslin T. (2010). Can the concept of ecosystem services be practically applied to improve natural resource management decisions? Ecological Economics, 69(5), 978-987. doi:10.1016/j.ecolecon.2009.12.011 
White, C., Halpem, S., \& Kappel, C. (2012). Ecosystem services tradeoff analysis reveals the value of marine spatial planning for multiple ocean uses. PNAS,109(12), 4696-4701. Retrieved from www.pnas.org/cgi/doi/10.1073/pnas.1114215109

Wolf A. (2004). Research Strategies for Policy Relevance. Social Policy Journal of New Zealand, 23 (2004): 65+.

Zheng W, Shi H, Chen S, \& Zhu M. (2009). Benefit and cost analysis of mariculture based on ecosystem services. Ecological Economics Ecological Economics, 68(6), 1626-1632. 


\section{Appendices}

Appendix A: Interview Questions asked during semi-structured interviews. Interview Biography Questions:

1. What is your current occupation?

2. What is you background that has led you to your current position?

3. How long have you worked in this field?

4. What do you see as your role in policy making?

Interview Substantive Questions:

1. What do you see as the goods, services, and other benefits that the coast and ocean provide to the community and state?

2. Going forward, what are necessary policies for these coastal and estuarine goods, services, and benefits?

3. How does your agency/organization play a role in policy making? And can you provide some specific example of this?

4. What scientific information do you currently rely on to advocate for or push for policies that will preserve these services or benefits?

5. Where do you seek information to enhance coastal policy outcomes? What information do you lack access to that might better help you in your efforts to enhance coastal outcomes? Or, can you think of tools/resources/opportunities that would be useful to obtain needed information?

6. Can you discuss an instance where you have experienced barriers in working with scientists to increase the use of scientific data in policy making?

7. Are there specific times when you have experienced hindrances in policy/management implementation?

8. Can you explain an occasion in which you have been impacted by cross-agency barriers in policy/management implementation? 
Appendix B: Interview Categorizing Descriptors Analyzed

\begin{tabular}{llllll} 
Division & $\begin{array}{l}\text { Dominant } \\
\text { Scope }\end{array}$ & Gender & $\begin{array}{l}\text { Geographic } \\
\text { Location }\end{array}$ & Personal Role & $\begin{array}{l}\text { Years in } \\
\text { the field }\end{array}$ \\
\hline - Municipal & $\bullet$ Local & $\bullet$ Male & $\bullet$ Coastal & $\bullet$ Develop policy & $\bullet 0-10$ \\
- State & $\bullet$ State & $\bullet$ Female & $\bullet$ Inland & $\bullet$ Provide & $\bullet 11-20$ \\
- NGO & $\bullet$ Regional & $\bullet$ Mixed & & data/influence & $\bullet 21+$ \\
- Federal & $\bullet$ National & & & Develop & \\
& & & & management \\
& & & & plans \\
\hline
\end{tabular}




\title{
Chapter 3 (Collective Construction Phase): Communicating Data Gaps under an Ecosystem Services Framework: Connecting scientific and decision making sectors
}

\author{
Abstract \\ Historical gaps in scientific data have prevented decision makers from infusing scientific \\ information into their management and policy schemes. There is increasing interest among \\ decision makers and scientists to apply coastal and marine resource science in the policy and \\ management process. Interpersonal strategies are often an effective means to communicate \\ and generate policy relevant scientific information. Here I present a workshop model designed \\ to bridge the gap between coastal and marine decision makers and scientists. I identify \\ successful components and areas for improvement as recommendations to design and conduct \\ similar workshops in the future. This workshop format effectively connected decision makers \\ and scientists to initiate an iterative process to generate and transfer policy relevant scientific \\ information into evidence-based decisions, an important element in protecting coastal and \\ marine resources.
}

\section{$\underline{\text { Introduction }}$}

When decision makers are involved in defining scientific research project goals upfront there is an increased likelihood of uptake and use of the research findings in policy and management decisions (Dobbins et al., 2007; Lavis et al., 2003). However, the majority of planning, design, and execution of research occur outside of and without contact with the decision making realm (Risien, 2009). There is a lack of dialogue between decision makers and scientists, resulting in the inadequate use of research findings in decisions (Stone, 2012). Yet, 
there is increasing acknowledgement of the need for decision makers and scientists to communicate effectively and transfer knowledge (Pituch et al., 2006; Murcia, 2009). There is a particular need in Oregon to develop information that can be incorporated into decisions for ocean and coastal resource management (Risien, 2009). Promoting tools that enhance the use of data in marine decision making will enhance society's ability to address pressing coastal problems (Risien, 2009). One tool is to raise awareness among researchers of the scientific data needs of decision makers. A second tool is to connect academic or agency scientists that work on particular issues with decision makers with relevant data needs. Using interpersonal strategies and bringing decision makers and academic scientists together to transmit knowledge and define more specific goals and projects may lead to more integrated scientific research (Pituch et al., 2006). Thus, both identifying and communicating the data gaps and connecting decision makers and researchers may be the most effective strategy to generate evidence-based policy and management practices.

In person interactions can be an effective model of collaborative communication to provide decision makers and scientists the opportunity to connect and relate to each other (Grorud-Culvert et al., 2010; Pituch et al., 2006). Davis et al. (2013) found that workshops in which face-to-face interactions connected natural resource scientists and decision makers provide an important opportunity for meaningful dialogue. Workshops have also been found to provide the opportunity 1) for decision makers to express to scientists the types of information they need and 2) to inform decision makers of scientific advances (Murcia, 2009). Here I test a method for establishing this connection: I designed and conducted a "synthesis session" (SS) - a workshop to build communication between decision makers and researchers based on 
previously determined data gaps (Chapter 2). I propose the SS as an appropriate networking opportunity (Jandl et al., 208) and means of increasing knowledge of data gaps among the scientific community and improving communication between relevant researchers and decision makers (Murcia, 2009). This approach can ultimately lead to increased scientific data use in policy and management.

The SS was preceded by interviews with decision makers to identify data gaps and the types of communication with researchers that were perceived as most effective (Figure 1). Research has shown that designing a workshop around current issues and concerns generates enthusiasm from participants (Oreszczyn and Carr, 2008). The interviews revealed that formal partnerships and informal networks with knowledgeable individuals were beneficial means of increasing scientific data use in natural resource management decision making (Figure 1). SS participants included both scientific researchers and decision makers. SS participants were presented the analyzed results of the interviews (Phase 1 ) including priority data gaps (Chapter 2: Figure 3), tools, opportunities and resources for data sharing (Figure 1), and challenges in working with scientists (Figure 2). The SS drew on these results to build connections and identify tools and opportunities to increase scientific data use in policy and management. 


\section{Tools, Opportunities, Resources for Data Share}

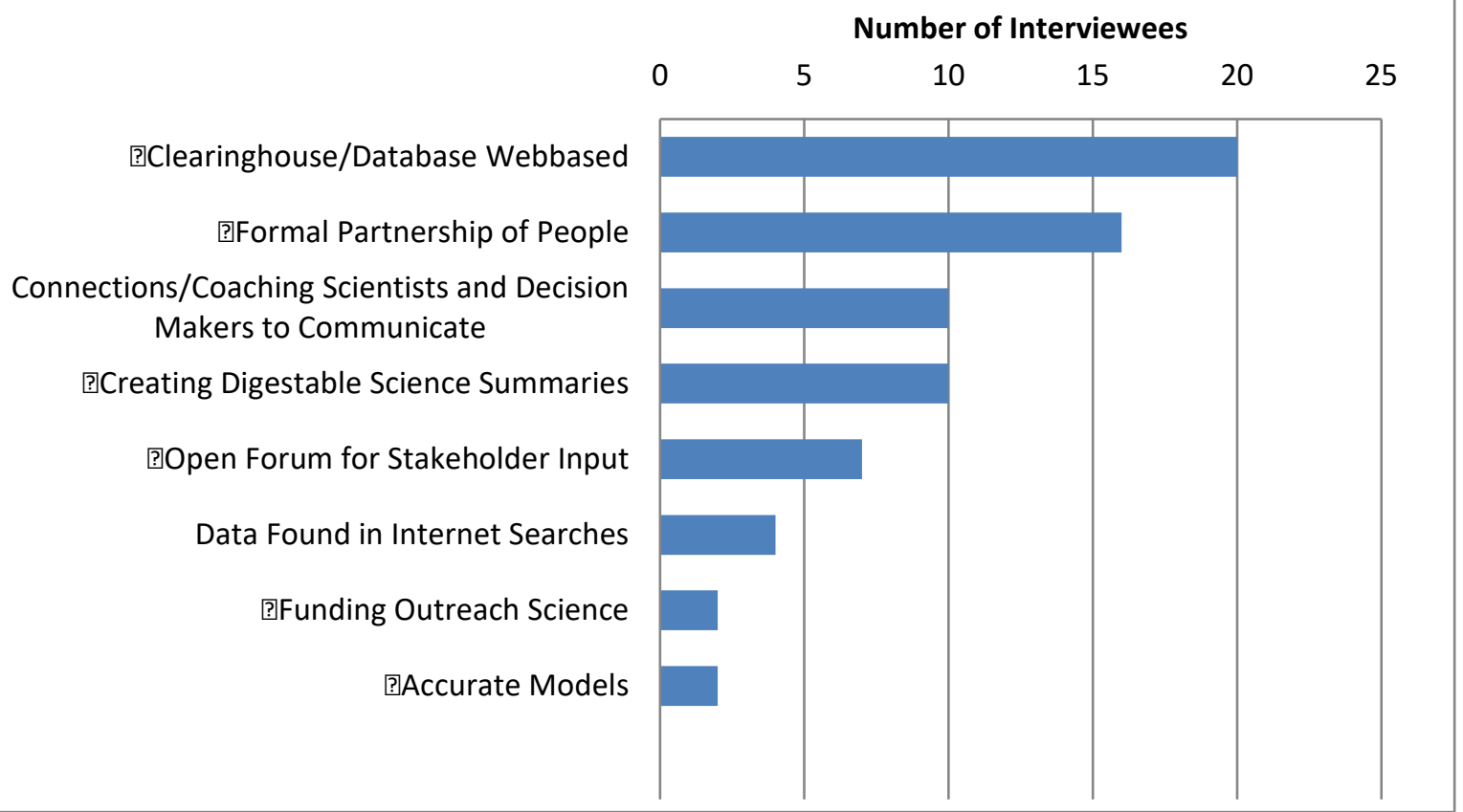

Figure 1: Tools, Opportunities, and Resources decision makers believe foster increased use of scientific data in decision making.

\section{Decision Makers' Perspective: Difficulties in Working With Scientists}

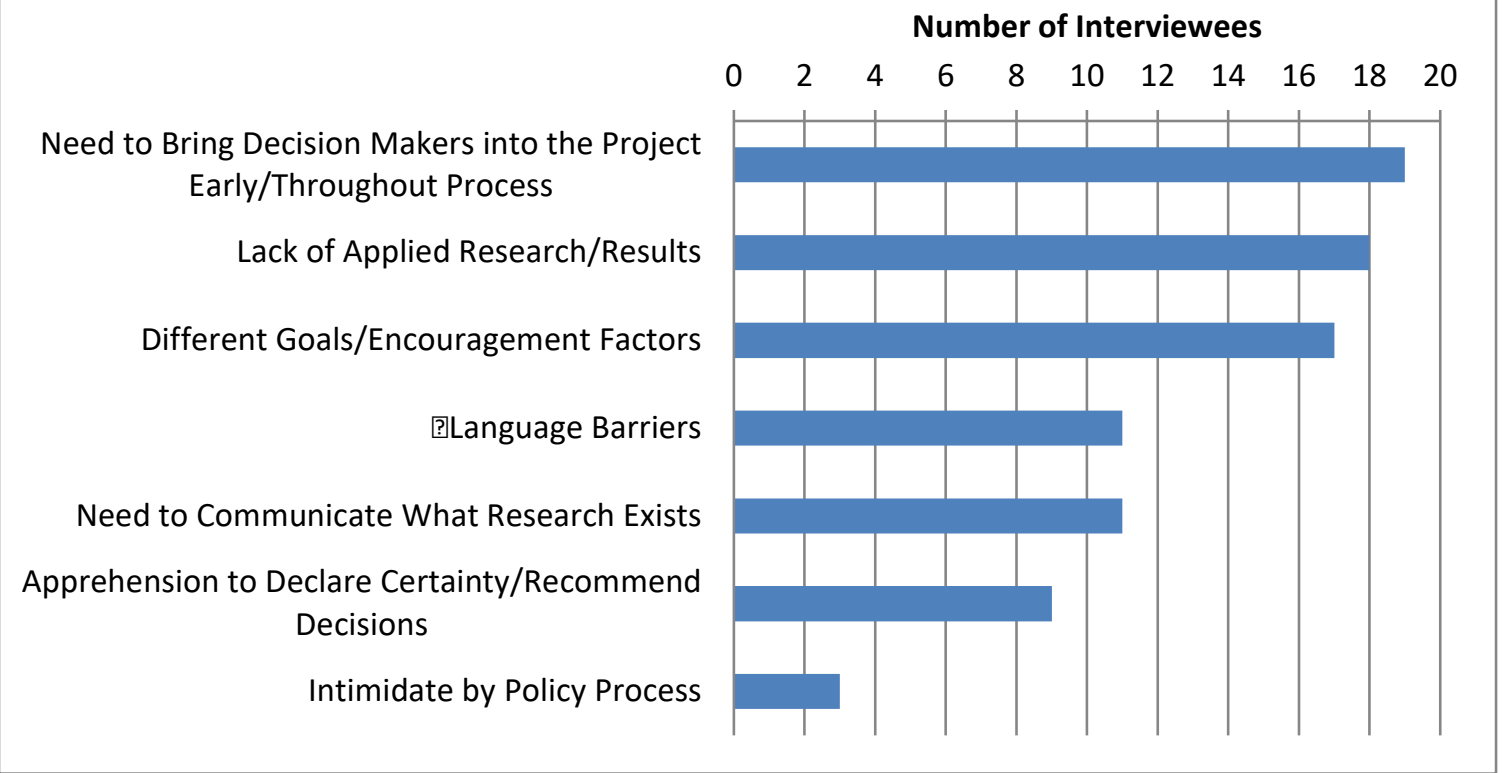

Figure 2: Decision makers' barriers in working with scientists to increase the use of scientific data in decision making. 
The SS directly addressed the interview finding that by bringing decision makers into the research project design phase the results could speak more directly to the existing decision maker data needs, while still meeting the goals of the researcher (Figure 2). Since language barriers and a lack of communication about existing research information were identified as barriers to using research in decision making (Figure 2), the SS aimed to address these challenges. In a recent study, $89 \%$ of decision makers in the Pacific Northwest thought that outreach programs were needed to inform policy and management decisions regarding climate change impacts (Lach et al., 2012). Thus, the SS is one possible tool for bridging data gaps through increasing connections and fostering communication between siloed sectors. Research conducted by Davis et al. (2013) revealed that similar workshops and synthesis sessions with fire science researchers and managers increased the efficient use of limited time and resources.

The SS aims to engage stakeholders from the beginning of the research process to increase 'buy-in' of the end product (National Research Council, 2012; Dobbins et al., 2007). In turn, better understanding decision maker needs can promote more relevant research and, ultimately, better policy enactment (National Research Council, 2012). Previous research has recognized that cross-sector knowledge production between decision makers and scientists can be an important element in more reflective and deliberative natural resource management (Renner et al., 2013). Thus, the SS was used to create mutually beneficial connections between decision makers and scientific researchers to eventually increase the creation and use of policy and management relevant research (Dobbins et al., 2007). 


\section{Methods}

I designed the SS in response to an expressed need to connect scientists and decision makers and built avenues for communication (Figure 2). A total of 51 decision makers from 28 agencies and organizations were invited to the event; invitees included those involved in the interviewing process (Phase 1) as well as decision makers who interviewees recommended. Thirty-five scientists involved in coastal and marine research relevant to the identified scientific data gaps and ecosystem service priorities (Chapter 2) were invited from Portland State University, University of Washington Vancouver, University of Oregon, and Oregon State University as well as university affiliated research organizations. A flyer was distributed to all invitees via email (Appendix C). The Hilton Garden Inn in Corvallis, OR was selected as the location for the event based on its central location to invitees coming from north and south, inland and the coast, and as a neutral site. Twenty-four individuals participated in the half-day session - from 10am to 3pm.

Three weeks prior to the workshop, participants were asked to prepare 3-5 minute minipresentations on either: 1) a policy or management project on which the participant was working that lacked sufficient scientific data or 2) ongoing or future research that related to policy and management in coastal/nearshore Oregon ecosystems. To assist in framing these mini-presentations, I shared with participants the action oriented goals for the event: 1) communicate current data needs 2 ) encourage cooperation between sectors (researchers and decision makers) to design research projects (e.g., ecosystem services related data needs) 3) generate a commitment to follow up with at least one attendee regarding potential projects. 
Participants were offered the opportunity to provide presentations with a maximum of 4 PowerPoint slides prior to the event.

Upon arrival, participants completed a standard pre-event survey designed to understand participants' expectations for the day (Pituch et al., 2006) (Appendix D). The workshop began with brief introductions that included each participant's name, organizational affiliation, and favorite marine organism. After a brief overview of the agenda (Appendix E), I presented on the ecosystem services priorities and scientific data needs identified through the interviews conducted in 2013 (Phase 1). Then all participants gave mini-presentations, with or without visuals (PowerPoint). During lunch, a discussion on "Opening Lines of Communication" took place, to enhance free flowing communication between the two sectors. Participants were encouraged to discuss barriers and difficulties in communicating with each other as well as opportunities to overcome these barriers to enhance collaborative work. Participants were then provided the opportunity to work through these barriers through a "speed dating" activity. During this exercise, individuals from different sectors were provided the opportunity to communicate one on one during 5 rotations. Scientists remained seated while decision makers rotated, selecting a scientist whose research they felt was most akin to their decision making needs (based on the mini-presentations). This activity allowed participants to have 5 mini-conversations for 8 minutes each. Since there were more decision makers than scientists, some 'one-on-one' discussions included three individuals. Participants were encouraged to ask questions that arose from mini-presentations and to discuss possible research projects that addressed the needs/interests of both individuals. After establishing these connections, participants were provided the opportunity to discuss as a group how to best sustain 
connections in a professional setting. This discussion, titled "Sustaining Connections" focused on best strategies for following-up with and creating projects with other participants. Finally, a brief wrap-up had participants reflect on the event by answering 3 questions on a quarter sheet piece of paper:

1) With whom will you follow-up (other attendee[s])?

2) When will you follow-up with this person?

3) What project(s) have you both discussed pursuing?

Participants then put the paper in a self-addressed envelope (provided). These envelopes were mailed one month post event as a reminder to participants to follow-up and sustain the connections they made during the workshop. After a brief thank you, the participants were asked to complete a post-event survey (Appendix F) to evaluate the successes as well as opportunities for improving workshops of this nature.

\section{$\underline{\text { Results }}$}

The workshop began at 10 am on May $30^{\text {th }}, 2014$ with 24 participants. Participants waned as the day progressed, with 17 individuals remaining at 3pm at the close of the workshop. Twenty-two of the 24 participants completed the pre-event survey identifying their expectations for the workshop. 


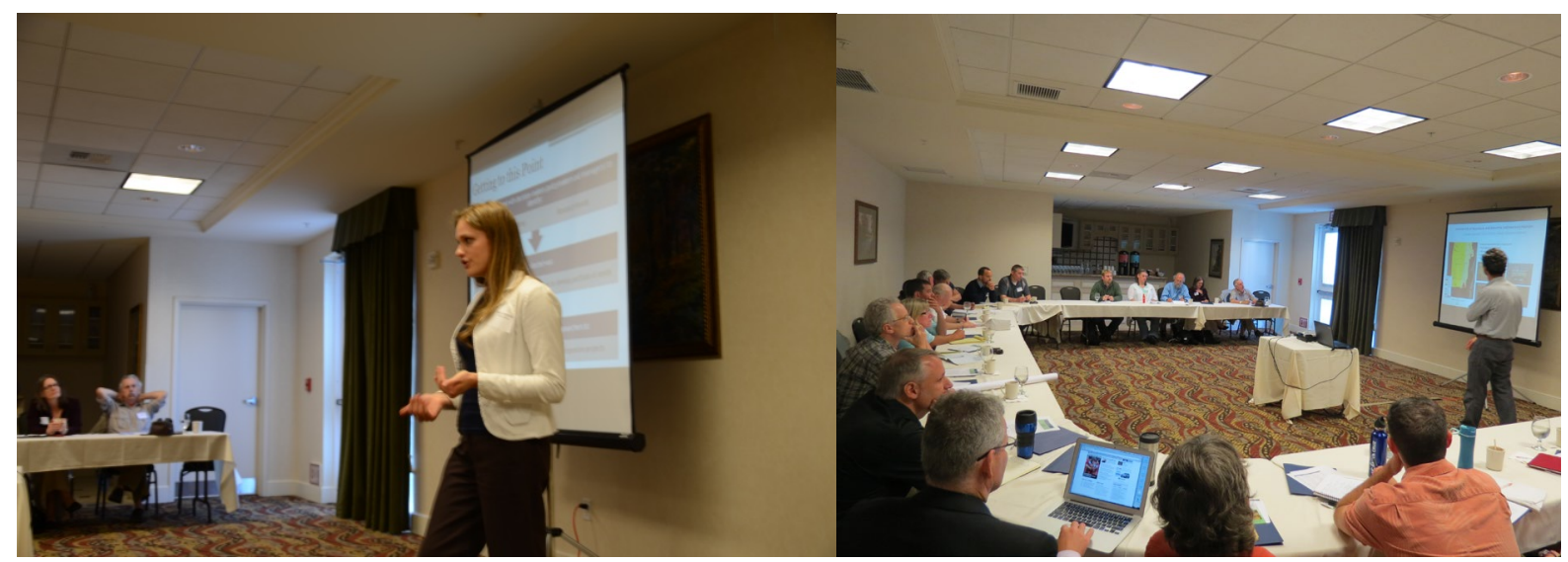

Photo 1: Opening presentation of the day, and mini-presentation (Photo Credit: Oregon Sea Grant).

The first question on the survey asked participants to select from a multiple choice list of what they expected to gain from the event, including "personal connections to decision makers", "personal connections to researchers", "learn key ecosystem services", "learn pressing data needs", "develop new collaborations", and "other" (Figure A).

\section{Expect to Gain from the Event}

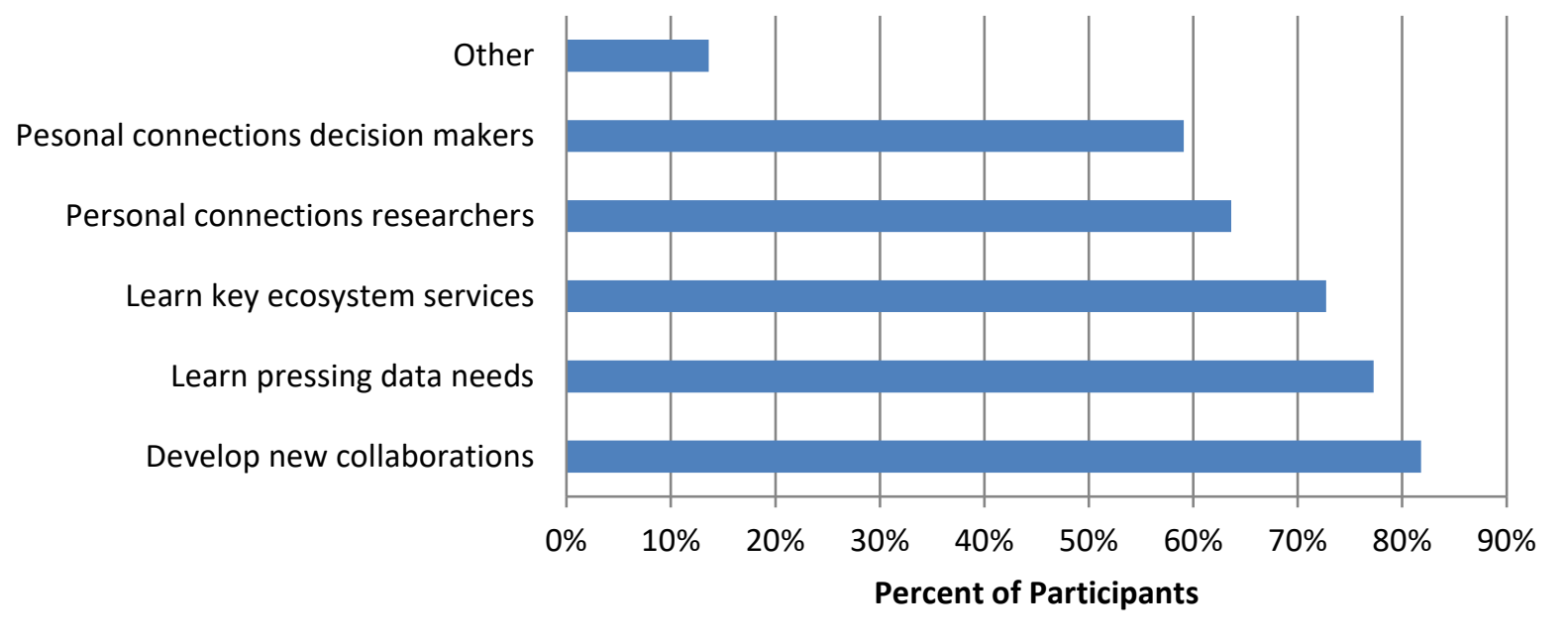

Figure 3: Pre-event survey results, on what participants expected to gain from the synthesis session.

Expectations for the day were high, with every multiple choice option, with the exception of

"other", selected by more than half the participants (Figure 3). The lowest among these, 
"personal connections to decision makers", was selected by 59\% of participants (Figure 3).

Primarily participants expected to "develop new collaborations" during the event, with $82 \%$ of participants selecting this option (Figure 3). Those who selected the "other" option expressed expectations to: 1) "share data and information needs with coastal resource management community" 2) "educate BOEM's [Bureau of Ocean Energy Management] process" and 3) "identify coastal management outreach needs".

The next question was open-ended allowing participants to discuss characteristics that result in a successful connection with practitioners across sectors (Figure 4).

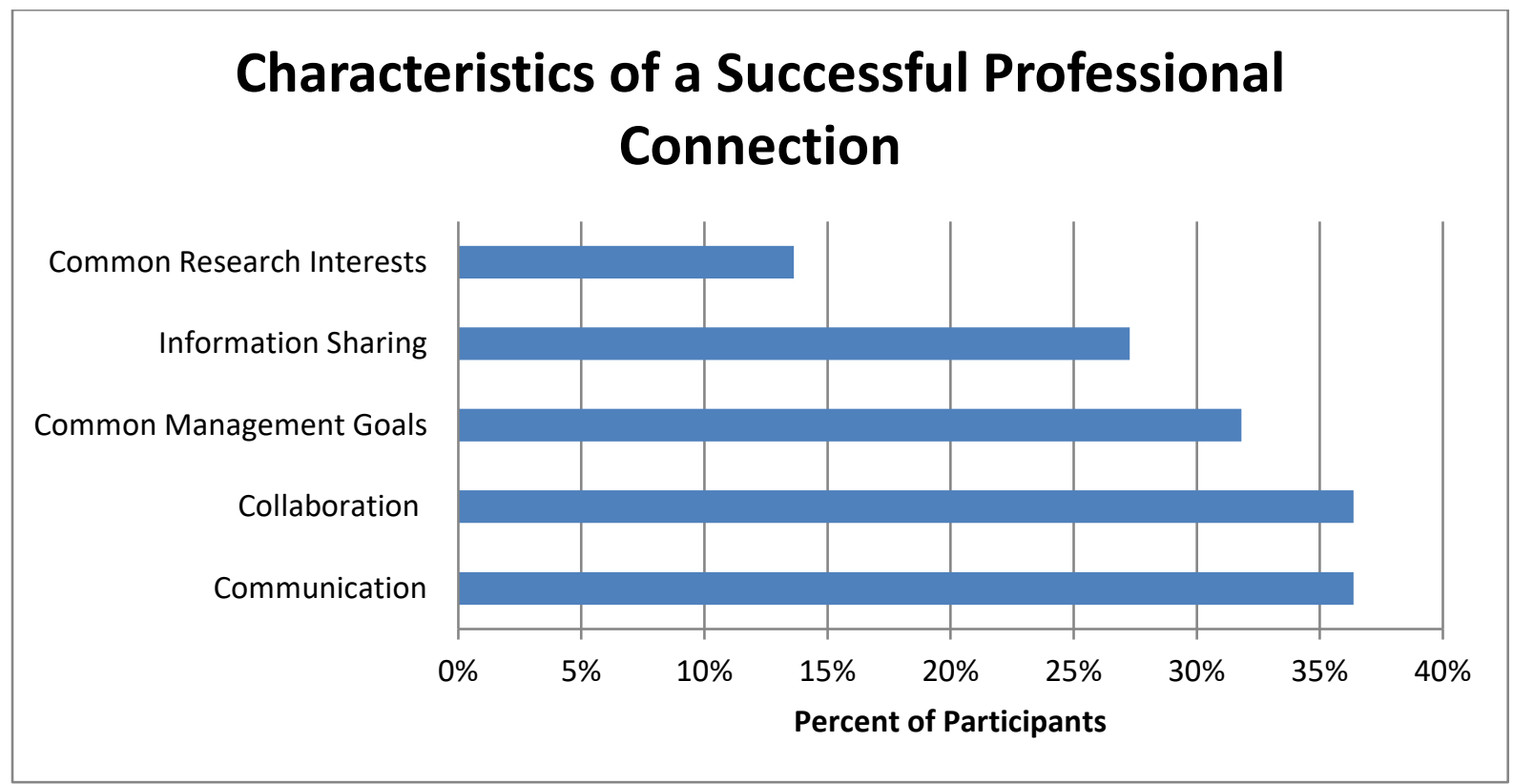

Figure 4: Participants provided 5 characteristics of a successful professional connection.

Communication and collaboration were tied as the number 1 characteristics of a successful

professional connection (Figure 4). One participant explained that communication was important because, "So much is being done in a vacuum and we need to be more efficient at distributing info., tech. transfer, minimizing duplication, etc.". In the words of one participant, collaboration involves "'success' for all parties within the context of their own world (academic, 
govt., political)". Roughly $1 / 3$ of participants felt that common goals were important for a successful professional connection (Figure 4). The ability to share relevant and needed information was an important characteristic according to over 1/4 of participants (Figure 4). According to $14 \%$ of participants, common interests are necessary for "successful" connections (Figure 4).

When asked to define what would inspire participants to follow-up with a personal connection made at the event, participants offered 7 different reasons (Figure 5).

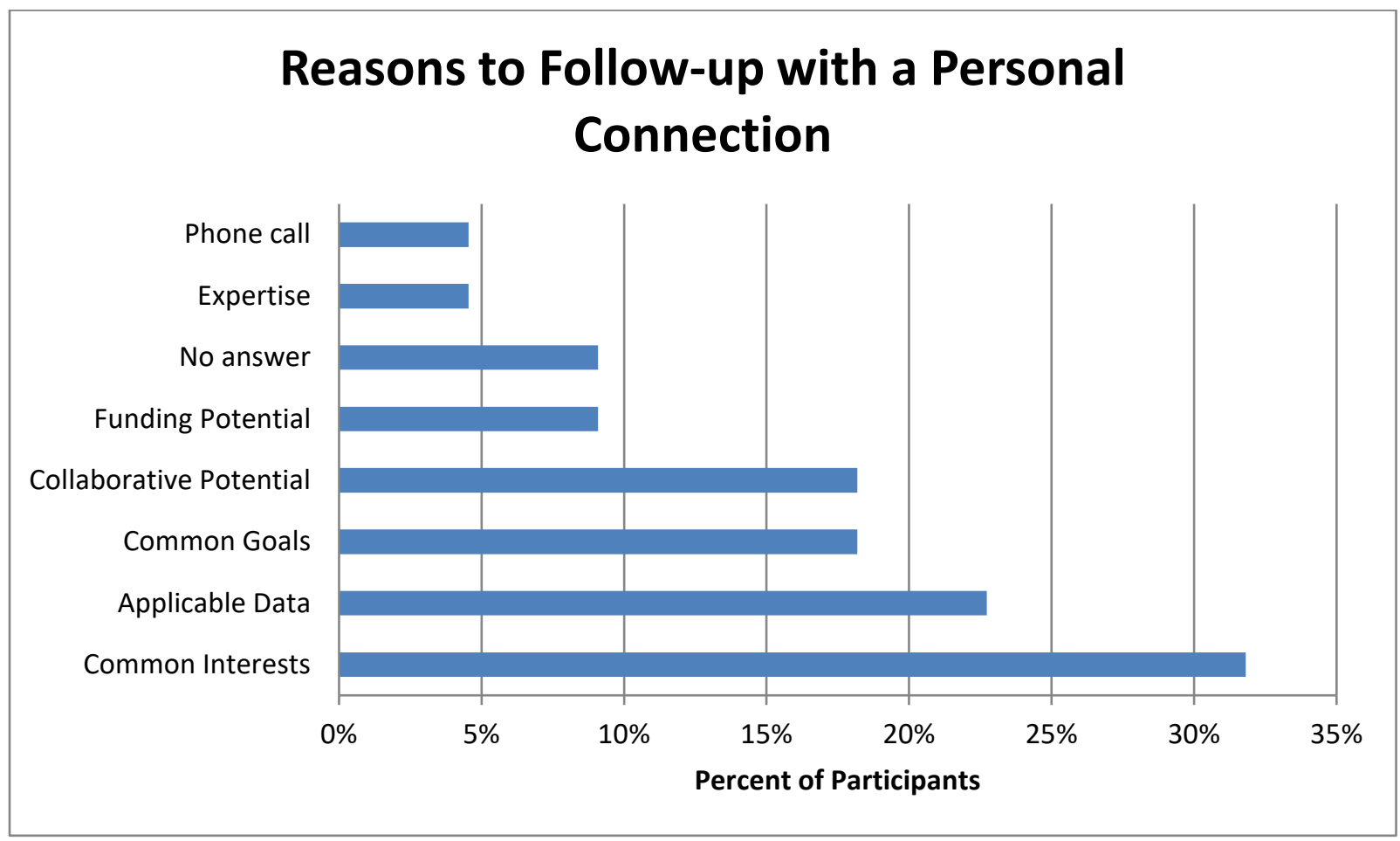

Figure 5: Participants offered 7 reasons they would be inspired to follow-up with a personal connection made during the day.

Having common interests was the number 1 reason participants would follow-up on connections made at the workshop (Figure 5). Twenty-three percent of participants expressed they would follow-up with a connection if the professional had relevant data (Figure 5). Common goals, which differed from common interests in that they were more applied to a 
natural resource policy action, were important to $18 \%$ of participants when following-up with other professionals at the workshop (Figure 5). Eighteen percent of participants also identified collaborative potential between themselves and another professional as a reason to follow-up.

Post-event surveys, completed by 17 participants, conveyed what participants gained from the workshop. Participants' overall experience was obtained through a multiple choice question with the option to select multiple responses (Figure 6). Sixty-five percent of participants considered "developed a new collaboration or connection" as the most significant experience from the day (Figure 6). The next three selections, each chosen by $59 \%$ of participants, were tied for the $2^{\text {nd }}$ most significant experience of the day; these included "learned more about pressing marine and coastal data needs", "made personal connections with decision makers", and "made personal connections with researchers" (Figure 6). Of the options provided, "learned more about key marine and coastal ecosystem services" was least selected, chosen by only $35 \%$ of participants (Figure 6). One individual selected the "other" option, and noted that s/he "had [the] opportunity to present research/data needs to colleagues". 


\section{Define the Days Experience}

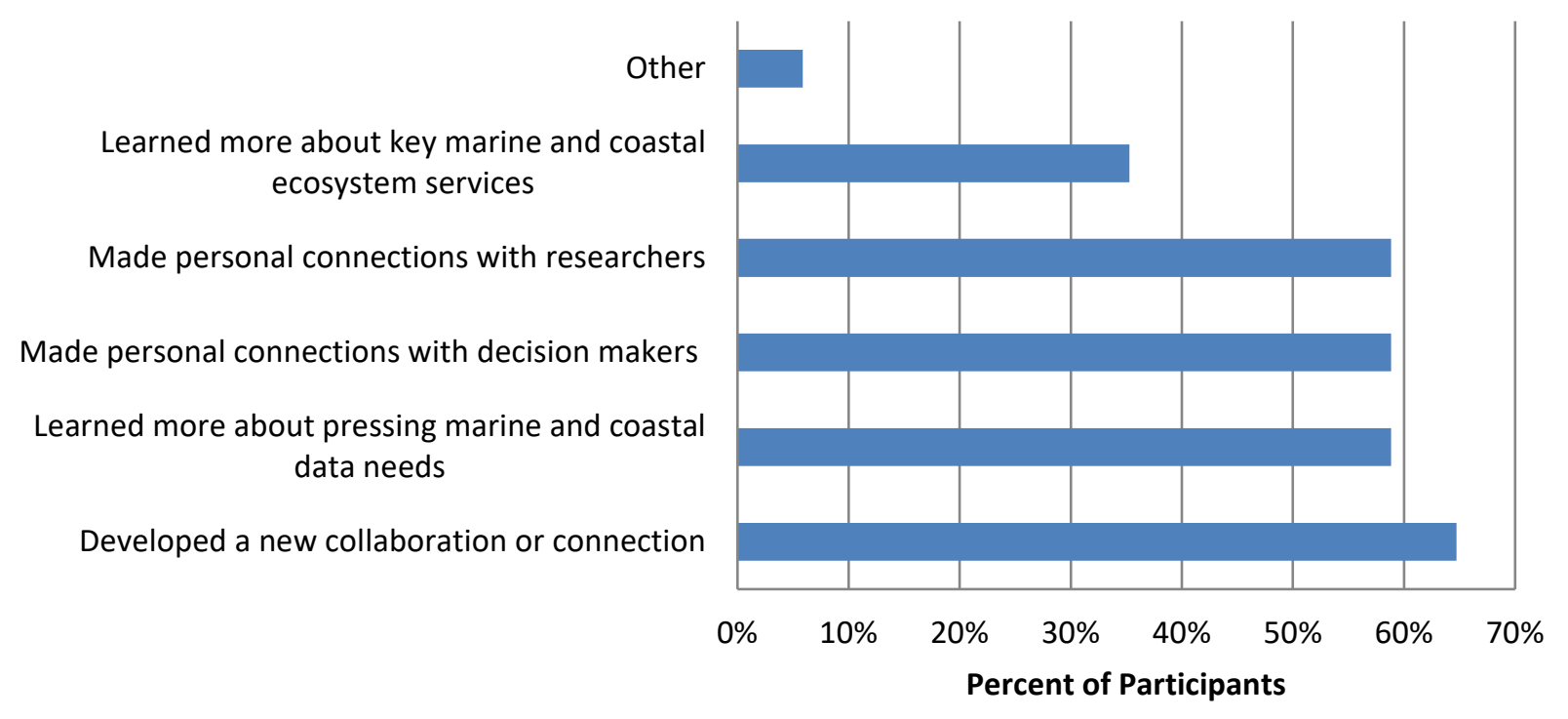

Figure 6: Responses to the multiple-choice question about participant experience during the day.

Participants were asked to report on the number of professionals they intended to

follow-up with post-synthesis session. They stated between 1 and 6 (Figure 7) with some

participants stating a range, in this case their answers were recorded in both number

categories. For example a participant that stated " $5-6$ " was marked as answering both 5 \& 6

connections. Two was the most commonly stated response with $35 \%$ of participants stating

they would follow-up with 2 connections, closely followed by 3 connections stated by $29 \%$ of

participants (Figure 7). 


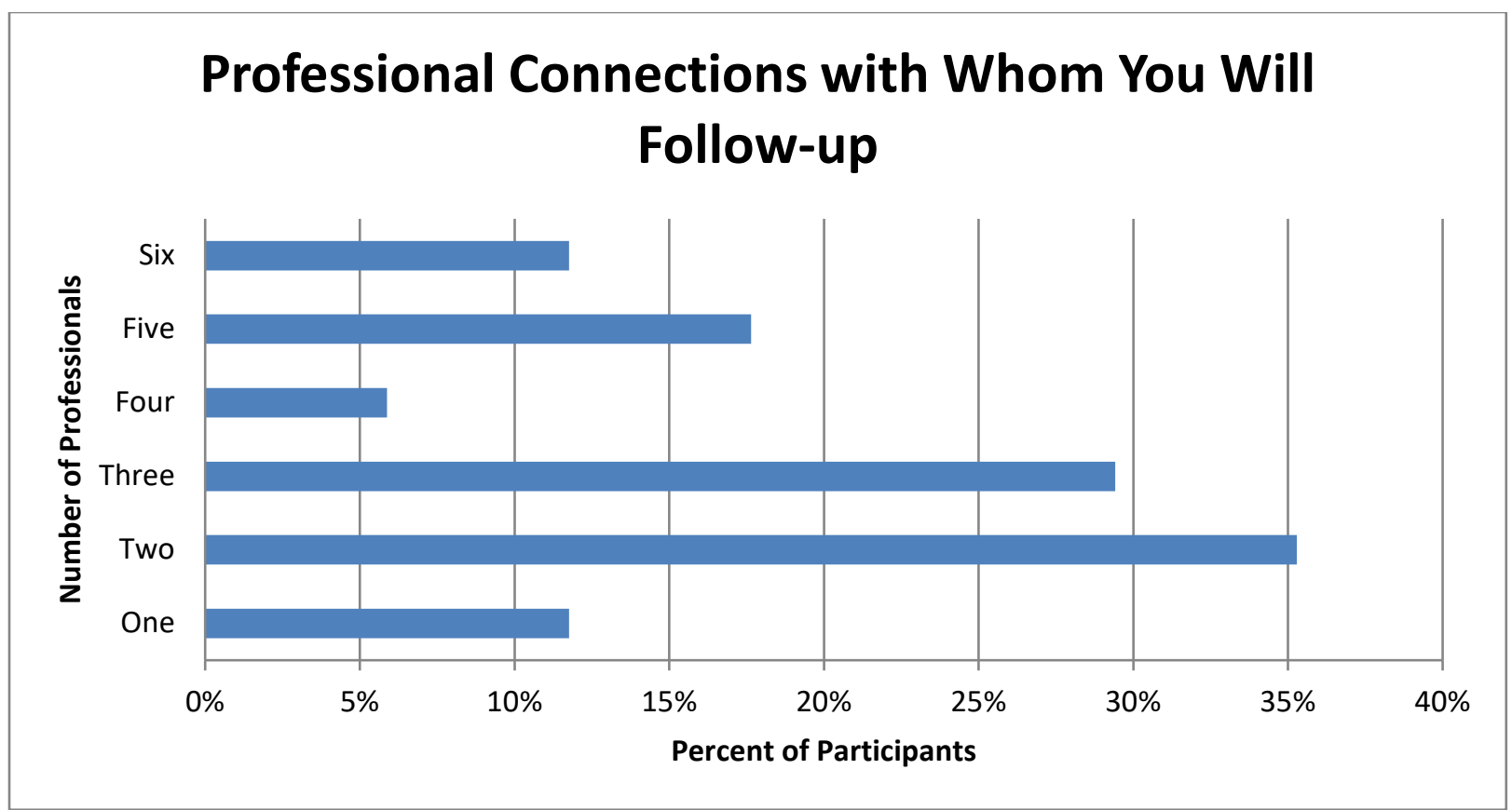

Figure 7: The number of professional connections with whom participants intend to follow-up.

The survey also asked participants to rank their top 3 activities for the day (Figure 8).

Some responders included benefits of the day. These responses have been noted as "other".

For example, one of the "other" responses was "feeling like my training and research questions matter". The majority (53\%) of participants ranked the mini-presentations as their favorite activity of the day with the speed dating session as the second most stated \#1 activity (Figure 8). Group discussions were the favorite activity of $6 \%$ of participants (Figure $8 a$ ). Answers for the $2^{\text {nd }}$ highest ranked activity were more diverse than for the $1^{\text {st }}$, including 6 different workshop activities (Figure $8 \mathrm{~b}$ ). The speed dating was chosen most often as the $2^{\text {nd }}$ favorite activity, selected by roughly $1 / 4^{\text {th }}$ of participants (Figure $8 \mathrm{~b}$ ). Mini-presentations and the first discussion of the day, titled "Opening Lines of Communication", were each stated as the $2^{\text {nd }}$ favorite event by $18 \%$ of participants, while the second discussion, titled "Sustaining Connections", the group discussions in general, and hearing and sharing data needs were each ranked $2^{\text {nd }}$ by $12 \%$ of participants (Figure $8 b$ ). Given that $12 \%$ of participants identified hearing 
and sharing data needs as a response, here it is listed as a separate 'favorite' activity as opposed to being included in the "other" category like most non-activity answers (Figure 8b).

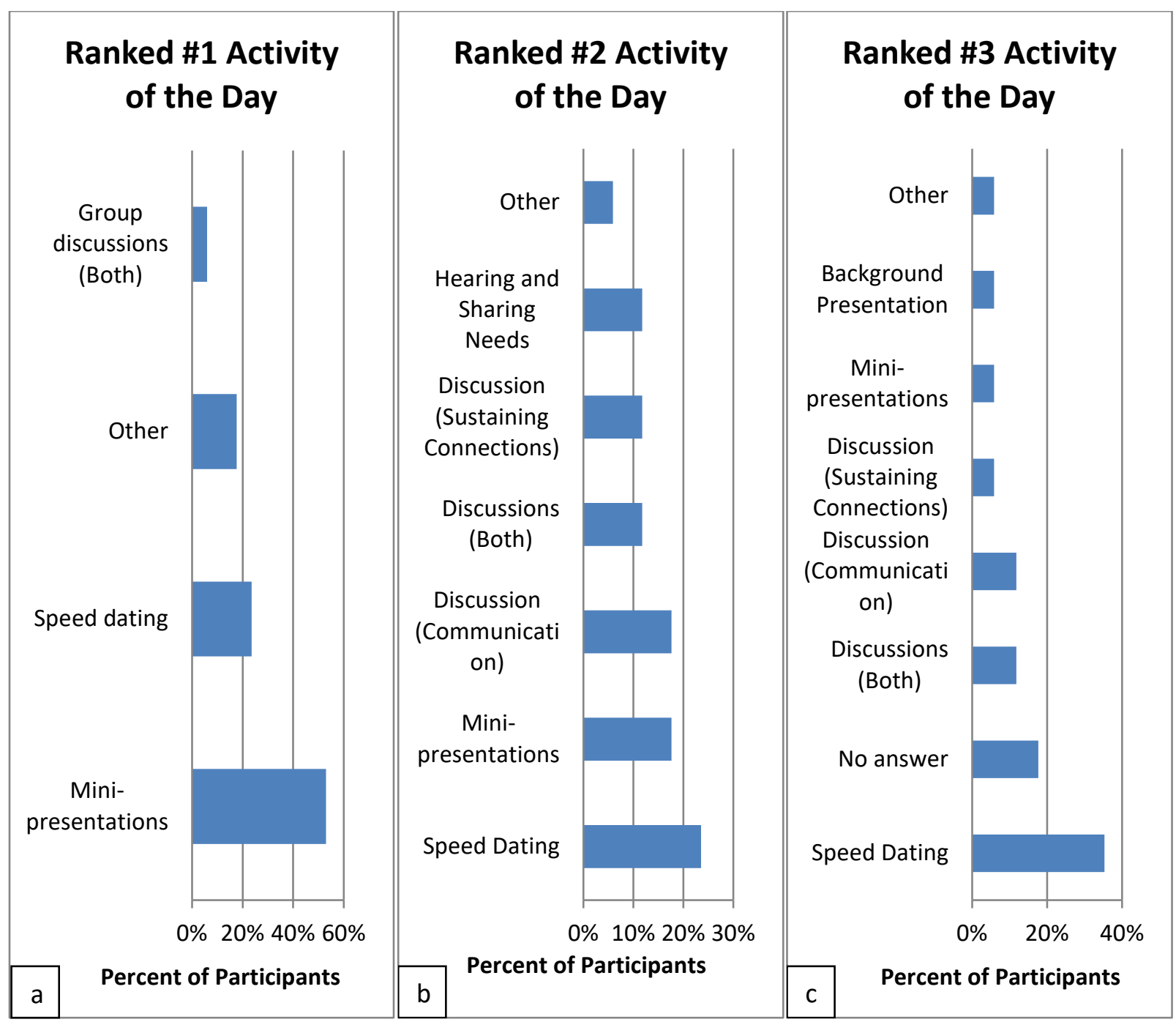

Figure 8: Activities ranked as the best of the workshop. Figure8a: Activities ranked number 1. Figure8b: Activities ranked number 2. Figure8c: Activities ranked number 3.

Answers for the $3^{\text {rd }}$ ranking were the most diverse of the 3 rankings (Figure $8 c$ ). Over $1 / 3^{\text {rd }}$ of participants chose the speed dating activity as their $3^{\text {rd }}$ favorite activity of the day (Figure $8 \mathrm{c}$ ), whereas $18 \%$ of participants chose to not provide a $3^{\text {rd }}$ ranking activity (Figure $8 \mathrm{c}$ ). The open discussions and the "Opening Lines of Communication" discussion were both ranked as the $3^{\text {rd }}$ favorite, by $12 \%$ of participants each (Figure $8 \mathrm{c}$ ). The "Sustaining Connections" 
discussion, the mini-presentations, and the initial background presentation on interviewing results were all chosen as $3^{\text {rd }}$ favorite by only 1 participant each (Figure 8c). Across the three rankings, the mini-presentations activity was listed by $77 \%$ of participants, and the speed dating activity was listed by $83 \%$ of participants.

\section{Discussion}

The synthesis session presented here provides a workshop format that successfully met the short term goals of this project. About 75 individuals were invited, 30 (40\%) accepted the invite, and $24(32 \%)$ were in attendance when the day began, thus indicating high interest in and enthusiasm for the goals of the workshop. The SS format was selected to build on previous successes of mini-presentations and speed dating from scientific society conferences (Jacobson, 2009) and to test its effectiveness in a venue aimed at linking scientists and decision makers. The synthesis session tested here provides a proof of concept for similar future events to address specific natural resource management issues in other locales and perhaps on other themes. As apparent by pre- and post-survey results, the majority of expectations that participants had at the beginning of the day were met through the format of the SS via the activities conducted. Participants (82\%) stated that they wanted to develop new collaborations. In post-surveys at least $65 \%$ of participants said they in fact did develop new collaborations. Roughly $77 \%$ of participants wanted to learn more about pressing marine and coastal data needs during the workshop. Post-event surveys revealed that almost $60 \%$ of participants felt better informed about these pressing needs. Furthermore, in pre-event surveys, participants expressed that communication, collaboration, common goals, sharing information, and having common interests were characteristics of a successful professional connection. Since the day's 
activities revolved around enhancing these characteristics, the SS was able to address the underlying features of forming successful collaborations. Thus, the new collaborations that participants made during the day are grounded in identified characteristics of successful collaboration. Though many expectations for the day were well addressed by the activities conducted, the workshop did not provide adequate activities for participants to learn about key marine and coastal ecosystem services. While $73 \%$ of participants were expecting to learn more about key ecosystem services during the workshop, only $35 \%$ felt at the end of the day that they had. This goal for the event was underachieved.

The post-event survey provides insights into which activities were most important in achieving the day's goals. The mini-presentations offered by all participants were the most popular activity of the day. Participants were able to communicate their research and policy interests, as well as learn about those of other professionals in the room. This meant that even for attendees unable to stay for the afternoon, they were more aware of who they could contact regarding particular issues. Speed dating was the second most successful activity of the day allowing participants to begin communicating with those individuals who expressed shared interests during mini-presentations, thereby providing the opportunity to broaden participant networks. The importance in broadening networks reflects back to the interview results (Figure 1) that show formal and informal interactions and communications between the decision making and scientific sectors as an important tool to increase use of research in decision making. The discussion titled "Opening Lines of Communication" was considered by participants as the third most beneficial activity of the day, and certainly began to break down the barriers in communication between sectors. 
Based on participant evaluations and organizer observations of the day, there are important recommendations to enhance similar workshops in the future. First, the content of the day though appropriate, lacked one key element. An additional discussion to decide upon a commonly agreed definition of important ecosystem services would have facilitated shared understanding and better achieved the goal of eliminating language barriers between sectors (Figure 2). Given that decision makers interpret ecosystem services slightly differently (i.e., categorizing them into the pillars of sustainability, Chapter 2) than scientists, a discussion could have helped participants be on the same page. Furthermore, during post-event surveys, one participant suggested that ecosystem services were not well defined by the group.

The "Opening Lines of Communication" discussion was overall successful, however it did not play out entirely as planned. At the start of the discussion participants were shown Figure 2 and asked to reflect on either 1) what challenges the scientific community has in working with decision makers and/or 2) ways to work through and overcome these challenges or existing barriers. As the discussion played out, it focused predominantly on this second point, how to overcome the barriers expressed by decision makers. One participant noted in their post-event survey that there should have been an opportunity for scientists to provide a reflection on their perspective of barriers. Thus, a future approach would be to split this discussion into two parts, one for each discussion point.

The discussion titled "Sustaining Connections" ended the day with an individual commitment from each participant to list with whom they would follow-up; a statement about what projects had been discussed with those participants, and a timeline for follow-up. In 
addition to this commitment, however, an additional piece of the process that would facilitate sustained networking would be to ask each group to come to a consensus on how to sustain the connection. Some time also should have been devoted to reflecting on what had been accomplished throughout the day (Oreszczyn and Carr, 2008), in order to solidify the success of such interactions and the worth of the time involved. These changes to content would have enhanced the wrap up piece of the SS.

Potential modifications to the timing, including making the SS a full day, would have enhanced its success. A full day SS would add two or three hours to the event to accommodate the recommended improvements of the workshop's content mentioned above. Attendees were asked to recommend activities to add to similar events in the future, 8 of the 14 participants who answered this question suggested more time for either a particular activity conducted or the day in general. Another timing modification involves the date of the event. The date of the event was planned around holidays and other known conferences and workshops. Despite best efforts, the day still fell on Oregon Legislative Days, and as a result some decision makers cancelled the day before or the day of the event due to unresolved legislative activities that emerged during legislative days. Before finalizing the event date, polling of potential participants could have avoided the scheduling conflict.

Finally, although space and location were generally suitable, there is room for future improvements. The conference room available at the hotel was small and intimate (Photo 1). Chairs and tables were organized in a horseshoe shape around a focal presentation projector (Photo 1). These aspects of the room provided an atmosphere for group discussion that was 
honest and robust (Jacobson, 2009). Holding the workshop in a hotel in Corvallis, OR was an appropriate location given that people came to the workshop from as far north as Seattle, WA and as far south as Newport and Eugene, OR. The hotel provided a neutral location for decision makers and scientists to come together. However, the proximity of the hotel to the Oregon State University campus may have conveyed an inaccurate perception that the event was sponsored, in part, by OSU. Therefore, though the location did not seem to alienate any participants, it is important for facilitators of future synthesis sessions to keep the location as neutral as possible.

Future workshops that attempt to connect the decision making and scientific communities to generate and obtain applied information for policy and management practices may find that a SS of this format, with the recommendations for improvement incorporated, can result in a high level of success. Workshops geared toward developing cross-sector communication have the potential to infuse greater scientific data into the decision making process, resulting in more effective and efficient policy and management practices (GrorudCulvert, 2010). The SS conducted here revealed that getting practitioners from these sectors in a room together to interact freely can effectively initiate necessary conversation to remedy existing data gaps (Oreszczyn and Carr, 2008). Opening these lines of communication through concentrated interactions brings relevant individuals together to realize their mutual interests and needs. By joining forces to address those interests and needs, professionals can generate scientific data that saves time and money for both sectors and has greater applicability to management and policy decisions (Cairns and Harris, 2011). However, to achieve these goals, both sectors must engage in following-up to sustain the connections made at the workshop 
(Renner et al., 2013). Sustaining connections requires post-event attention, including but not limited to listservs or blogs where participants can continue to discuss policy/management issues and applicable data as they arise. In a brief follow-up email survey, the participants of the SS indicated that a listserv was preferred over a blog for continued participation among this group (Appendix G) Additional booster workshops can foster continued sector communication and information generation (Pituch et al., 2006).

The policy and management process is often messy, uncertain, and unstable; thus research and evidence are needed to analyze alternatives that arise in this process (Oreszczyn and Carr, 2008). There is hence a need to connect the decision making and scientific sectors in an iterative process to develop and infuse applied research into decisions. Having the initial face-to-face workshop format allows for trust to be built (Cairns and Harris, 2011) and new knowledge to be generated (Oreszczyn and Carr, 2008). The SS discussed here was successful in the short term and has the potential to effectively answer decision making questions by infusing applied scientific information into the process, as well as by making new or reinvigorating existing professional connections. The SS offered a sounding board for intellectual pursuits to flow, and thus provides a real potential to make significant and lasting change (Cairns and Harris, 2011) in marine and coastal resource management. This format can thus act as a model for workshops across the country attempting to bring scientists and decision makers together for the goal of generating evidence-based decisions.

\section{References}

Cairns C, Harris M (2011) Local Cross-Sector Partnerships: Tackling the Challenges Collaboratively, Nonprofit Management \& Leadership, 21(3):311-324, DOI 10.1002/nml 
Costanza R, Alperovitz G, Daly HE, Farley J, Franco C, Jackson T, Kubiszewski I, Schor J, Victor P. 2012. Building a sustainable and desirable economy-in-society-in-nature. New York: United Nations Division for Sustainable Development.

Davis, E., Moseley, C., Olsen, C., Abrams, J., Creighton, J. (2013). Diversity and dynamism of fire science and user needs. Journal of Forestry, 111(2), 101-107.

Dobbins M, Rosenbaum P, Plews N, Law M, Fysh A. (2007). Information transfer: what do decision makers want and need from researchers? Implementation Science. 2(20): 1-12.

Grorud-Culvert, K., Lester, SE., Airamé, S., Neeley, E., Gaines, SD., Levin, SA. (2010). Communicating marine reserve science to diverse audiences. Proceedings of the National Academy of Sciences of the United States of America, 107 (43), 18306-18311.

Jacobson, SK (2009) Communication skills for conservation professionals $2^{\text {nd }}$ ed., Island Press, Washington DC

Jandl R, Borsdorf A, Siegel G (2008) COST Strategy Workshop, Mountain Research and Development, 28(2):172-173. DOI: http://dx.doi.org/10.1659/mrd.1017

Lach D, Parker A, Boesl M. (2012). Assessing Regional Climate Needs. Pacific Northwest Climate Decision Support Consortium.

Lavis JN, Robertson D, Woodside JM, McLeod CB, Abelson J, the Knowledge Transfer Study Group (2003) How Can Research Organizations More Effectively Transfer Research Knowledge to Decision Makers?, The Milbank Quarterly, 81(2): 221-248

Murcia C, Gustavo K (2009) Application of Science to Protected Area Management: Overcoming the Barriers, Annals of the Missouri Botanical Garden, 96(3):508-520, DOI: http://dx.doi.org/10.3417/2008031

National Research Council. (2012). Using Science as Evidence in Public Policy. Committee on the Use of Social Science Knowledge in Public Policy, K. Prewitt, T.A. Schwandt, and M.L. Straf, Editors. Division of Behavioral and Social Sciences and Education. Washington, DC: The National Academies Press.

Oreszczyn S, Carr S (2008) Improving the link between policy research and practice: using a scenario workshop as a qualitative research tool in the case of genetically modified crops, Qualitative Research, 8(4): 473-497 
Pituch KA, Lawson KA, Wilcox RE, Littlefield JH, Miller JD, Erickson CK (2006) A Multisite Evaluation of a Communication Skills Workshop for Scientists, Journal of Teaching in the Addictions, 4:2, 1-22, DOI: 10.1300/J188v04n02_01

Renner R, Schneider F, Hohenwallner D, Kopeinig C, Kruse S, Lienert J, Link S, Muhar S (2013) Meeting the Challenges of Transdisciplinary Knowledge Production for Sustainable Water Governance, Mountain Research and Development, 33(3): 234-247

Risien, J. (ed.). (2009). West Coast Regional Marine Research and Information Needs. Oregon Sea Grant. ORESU-Q-09-001. Corvallis, OR.

Stone D (2002) Using Knowledge: the dilemmas of 'Bridging Research and Policy', Compare: A Journal of Comparative Education, 32(3):285-296, DOI: 10.1080/030579202200000745 4 


\section{Appendices}

\section{Appendix C: SS invitation flyer}

\section{INACaMMP Conference:}

Reflecting on scientific data needs for coastal and marine natural resource management

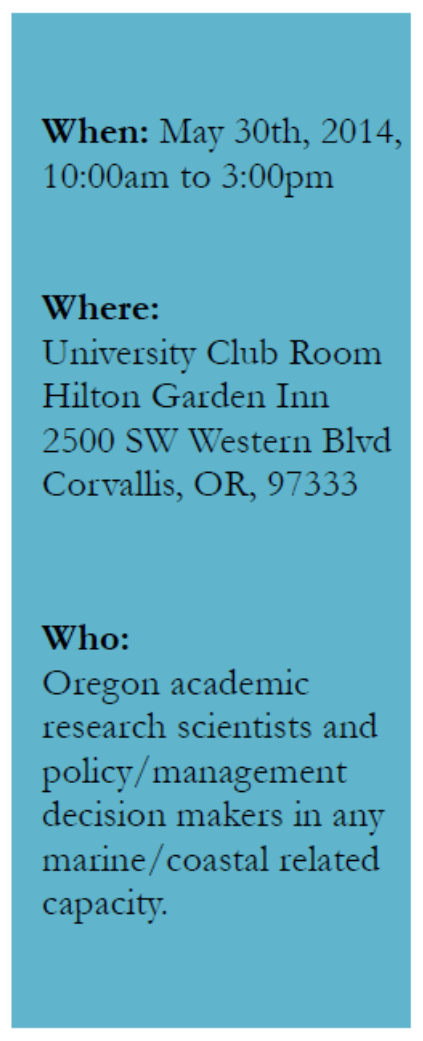

\section{What:}

The Synthesis Session will be a half-day collaborative session highlighting the scientific data gaps and needs in Oregon coastal and marine policy and management as expressed by coastal decision makers. This session will provide an opportunity for information sharing between coastal and marine decision makers and academic natural and social scientists.

The synthesis session will provide practitioners an opportunity to collaborate in the development of pragmatic and policy relevant research for applied, sciencebased policy and management. Coastal and marine decision makers and academic scientists in coastal and marine ecology, oceanography, sociology, and related research fields are invited to participate in this workshop.

The synthesis session will include short presentations, "speed dating", and other significant opportunities to connect and create mutualistic relationships moving forward. This will be a phenomenal opportunity to exchange knowledge and ideas with key individuals impacting Oregon Coastal resources

\section{Coordinating and Supporting Organizations:}

This Symposium is being convened by the INACaMMP project research team

Kaity Goldsmith, Masters of Environmental Managmenet candidate,

Dr. Elise Granek, Environmental Science and Management, Portland State University,

Dr. Amy Lubitow, Sociology, Portland State University,

Major support for the synthesis session has been generously provided by Oregon Sea Grant.

\section{Portland State}

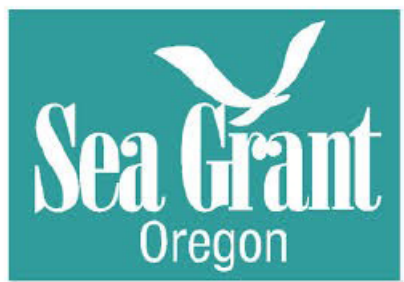


Appendix D: Pre-Event Survey of Expectations

2014 INACaMMP Conference for Ecosystem Services and Scientific Data Needs Under

Changing Climatic, Land Use, and Demographic Conditions

PARTICIPANT PRE-CONFERENCE EXPECTATIONS

Gender: Male $\quad$ Female

Professional Role (circle all that apply): Scientific Researcher Policy Maker Manager

Geographic location of job post (circle one): Inland Coastal

What do you expect to gain from this event? (Choose all that apply):

A. Learn more about key marine and coastal ecosystem services

B. Learn more about pressing marine and coastal data needs

C. Make personal connections with decision makers

D. Make personal connections with researchers

E. Develop new collaborations or connections

F. Other:

With the goal of reducing data gaps in mind, what characteristics result in a successful professional connection with practitioners across sectors (i.e. scientific researchers and/or policy makers and/or managers)?

What would inspire you to follow up with a personal connection you make during this conference?

How do you hope today's event enhances your capacity to communicate with individuals in other sectors? 


\section{Appendix E: INACaMMP Synthesis Session Agenda}

\section{Information Needs Assessment for}

Coastal and Marine Management and Policy in the Pacific

Northwest (INACaMMP): Project:

Ecosystem services under changing climatic, land use and demographic conditions

University Club Room

Hilton Garden Inn

2500 SW Western BIvd

Corvallis, OR 972333

INACaMMP CONFERENCE: REFLECTING ON SCIENTIFIC DATA NEEDS

FOR COASTAL AND MARINE NATURAL

RESOURCE MANAGEMENT

\section{Conference Agenda}

May 30th, $2014 \quad$ 10:00am-3:00pm

\begin{tabular}{|l|l|}
\hline Timeframe & Activity \\
\hline 10:00am-10:20am & $\begin{array}{l}\text { Registration, Pre-Event Survey, and Introduc- } \\
\text { tions }\end{array}$ \\
\hline 10:20am-10:50am & $\begin{array}{l}\text { Presentation: Ecosystem Services and Data } \\
\text { Gaps }\end{array}$ \\
\hline 10:50am-12:30pm & Participant Mini-presentations \\
\hline 12:30pm-12:45pm & Break and Lunch distribution \\
\hline 12:45pm-1:15pm & $\begin{array}{l}\text { Lunch, Discussion: Opening Lines of Communi- } \\
\text { cation }\end{array}$ \\
\hline 1:15pm-2:15pm & Science-Management "Speed Dating" \\
\hline 2:15pm-2:45pm & Discussion: Sustaining Connections \\
\hline 2:45pm-3:00pm & Wrap Up, Post-Event Survey \\
\hline
\end{tabular}

Sed fint \& Portland State

On behalf of the INACaMMP Project team, thank you for attending.

Please direct questions or comments to Kaity Goldsmith at kaitygoldsmith@yahoo.com 
Appendix F: Post-Event Evaluation

2014 INACaMMP Conference for Ecosystem Services and Scientific Data Needs Under

Changing Climatic, Land Use and Demographic Conditions

PARTICIPANT CONFERENCE EVALUATION

Gender: Male ___ Female

Professional Role (circle all that apply): Scientific Researcher Policy Maker Manager

Geographic location of job post (circle one): Inland Coastal

Which of the following accurately represents your experience today? (Choose all that apply):

A. Learned more about key marine and coastal ecosystem services

B. Learned more about pressing marine and coastal data needs

C. Made personal connections with decision makers

D. Made personal connections with researchers

E. Developed a new collaboration or connection

F. Other:

How many new professional connections have you made today with whom you expect to:

A. Follow up?

B. Plan research project(s)?

Roughly when do you plan to follow up with individuals with whom you have connected at this event?

Please rank the top 3 activities from today's event:

1.

2.

3.

What would you recommend be added to this type of event in the future?

Please list the one thing you would omit from future events of this nature: 
Appendix G: Follow-Up Email Survey Results

\section{Question 1}

Would you be interested in joining a listserv for sharing marine and coastal data and data needs?

\begin{tabular}{l|c}
\hline Answer Choices- & Responses- \\
\hline $\begin{array}{l}\text { Yes, I would join the Oregon Coastal \& Marine Data Network listserv (mentioned during } \\
\text { SS, http://www.coastalmarinedata.net/). }\end{array}$ & $81.82 \%(9)$ \\
\hline Yes, I would like a separate listserv created for the INACaMMP workshop attendees. & $45.45 \%(5)$ \\
\hline Not at this time. & $9.09 \%(1)$ \\
\hline Other (please specify) & $9.09 \%(1)$ \\
\hline
\end{tabular}

Total Respondents: 11

\section{Question 2}

If the INACaMMP project team started a blog for sharing data and data needs would you be interested?

\begin{tabular}{l|c}
\hline Answer Choices- & Responses- \\
\hline Yes, I would check the blog, ask questions, and upload data where applicable. & $\mathbf{1 8 . 1 8 \% ( 2 )}$ \\
\hline Yes, but I would only check the blog. & $\mathbf{2 7 . 2 7 \% ( 3 )}$ \\
\hline Not at this time. & $\mathbf{2 7 . 2 7 \% ( 3 )}$ \\
\hline Other (please specify) & $\mathbf{2 7 . 2 7 \% ( 3 )}$ \\
\hline
\end{tabular}

Total Respondents: 11

\section{Question 3}

Would you prefer a blog or listserv to sustain professional connections?

\begin{tabular}{l|c}
\hline Answer Choices- & Responses- \\
\hline Listserv & $45.45 \%(5)$ \\
\hline Blog & $18.18 \%(2)$ \\
\hline Both & $27.27 \%(3)$ \\
\hline Neither & $9.09 \%(1)$
\end{tabular}

Total Respondents: 11 


\section{Chapter 4: Conclusion}

I have proposed and tested a method to overcome institutional barriers and build crosssector communication capacity between decision makers and scientists that mutually benefits those involved while promoting their respective roles in society (Cairns and Harris, 2011; Roux et al., 2008). Preserving and protecting critical coastal and marine resources becomes ever more important as climatic, land use, and socio-demographic shifts occur. Doing so will require effective and efficient policy and management schemes that include the best available science, i.e., evidence-based decisions. This research engaged decision makers and scientists to begin a collaborative approach to extract, design, and integrate relevant information into evidencebased policy and management practices. A collaborative process allows scientists and decision makers to fine-tune the knowledge transfer to the particular political, economic, and environmental circumstances faced (Lavis et al., 2003). Open communication also begins to break down the language barriers between sectors, allowing decision makers to more accurately extrapolate and apply information to local conditions (Murcia, 2009), as well as be involved in the early stages of developing applied research projects (Oreszczyn and Carr, 2008). This integrated approach maximizes use of information to prevent, and in some cases reverse, the negative effects of human practices (Murcia, 2009), such as anthropogenic climate change and socio-demographic shifts.

An increased appreciation for the complexity of the decision making process can result from this move towards a model of inclusion and participation in the policy process (Oreszczyn and Carr, 2008). Creating a decision-relevant culture among researchers and a research-attuned 
culture among decision makers provides a two-way exchange of information that betters society at large (Lavis et al., 2003; Oreszczyn and Carr, 2008).

This interaction can be developed at many stages in the process (Lavis et al., 2003). Here I have focused on the issues that arise in the supply side dynamic for research in decision making (Stone, 2012). Further efforts to improve the supply side, i.e., improve the supply of policy-relevant data, would be to encourage funding agencies to stimulate bridging the gap between scientists and decision makers (Murcia, 2009). Many funders have begun to promote collaborations (Cairns and Harris, 2011), and require policy-relevant research (Stone, 2012); yet there is little known about how effective these funding mechanisms are for generating policyrelevant data. Evidence of strong decision impact of projects funded in this manner would enhance this mechanism. Further efforts to design platforms for sustained communication are also needed to supply information to decision makers (Jandl et al., 2008).

This interaction between sectors can also be addressed on the demand side, though additional research is required to analyze this dynamic (Stone, 2012). Such research would address the issues preventing incorporation of research into policy and management plans (Murcia, 2009), including 1) ignorance of policy-relevant research among decision makers, 2) tendency to fear intellectualism in policy, 3) process timing dynamics (i.e., research's lengthy process in conjunction with the immediate attention decisions can require), and 4) politicization of research (Stone, 2012). Awareness and absorption of research and developing a culture of learning in the decision making realm are means of resolving demand side issues (Stone, 2012).

Finally, issues that arise during the process of incorporating science into decisions due to the 'policy current', i.e., the societal context surrounding the political process that can 
change the circumstances within which research and policy are conducted, must be addressed in order to successfully achieve policy goals (Stone, 2012). These issues can arise from conflicts that come up in the political realm while building bridges between the science and decision making sectors (Stone, 2012). Due to the 'policy current', emphasis is made to the importance of sustained connections and long-term engagement between sectors (Stone, 2012; Roux et al., 2008). In doing so, changes to projects or flow of additional information can react to the 'policy current'. In this project, I have built a solid base of productive two-way discourse upon which continued dialogue can and should occur (Stone, 2012). A clear linkage between decision makers and scientists, electronic networks, decision support tools, and ecological models can all support a sustained effort (Ruth et al., 2003). Listservs and booster workshops are also recommended to coordinate long-term engagement efforts.

Increasing communication between scientists and decision makers results in an impressive return on monetary investments (Murcia, 2009), generating greater value for research dollars spent by developing more effective research (Oreszczyn and Carr, 2008). Thus, by enhancing social capital through communication, decision makers can better protect natural capital (Renner et al., 2013). Individuals and agencies who partake in cooperative efforts exercise community leadership, as this interaction requires a dedicated time investment to build mutual trust and understanding (Cairns and Harris, 2011). The 2 phase model of interaction designed and presented here should be considered a starting point for continued dialogue (Lavis et al., 2003).

Sustained interactions will allow participants of both sectors to overcome hindrances in communication and understanding, including a lack of common language between sectors 
(Cairns and Harris, 2011). Here I have suggested using an ecosystem services framework as a language bridge for more effective interactions. Continued debate about whether ecosystem services should be the focus of management action is not a sufficient argument against moving forward (von Stackelberg, 2012). I have demonstrated how using this framework within the interactive cross-sector decision making process can help define critical resource priorities in a holistic manner. There are real economic and ecological costs associated with continued consumption of finite resources (von Stackelberg, 2012).

The most important outcome of testing this 2 phase model for evidence-based decision making is in establishing a significant opportunity to sustain and continue to build cross-sector cooperation between decision making and scientific sectors in coastal Oregon, and thus more efficiently and effectively protect and preserve the ocean's critical natural capital. Testing this model in coastal Oregon serves as a demonstration of the potential opportunities provided by conducting the same model for evidence-based decision making in other for a across the country for a variety of ecosystem and political dynamics.

\section{Limitations}

The connections established in this project are only the first steps to the long-term engagement required to develop evidence-based decisions. Efforts are needed to sustain the connection moving forward. Listservs and booster workshops can be critical tools used to sustain these connections.

Evidence-based decision making is one tool to be used in generating effective policy and management schemes. Other forms of knowledge flow that engage the stakeholders missing in 
evidence-based decision making, i.e., the general public, are still necessary in many decisions to obtain the variety of relevant, interested perspectives.

\section{Acknowledgement}

I thank Oregon Sea Grant for continued support of this project. This manuscript has been inspired by work conducted by Michael Papenfus PhD of the US Environmental Protection Agency. His involvement and input is greatly appreciated. I appreciate input from Peter Ruggeiro PhD and John Stevenson of the Pacific Northwest Climate Impacts Research Consortium in project development. Analysis of the interviewing data would not have been possible without the assistance of Max Nielsen-Pincus PhD from Portland State University, Environmental Science and Management. I would like to thank Elise Granek PhD and Amy Lubitow PhD for their encouragement and constructive criticism in every step of this project.

\section{Additional References}

Roux DJ, Ashton PJ, Nel JL, MacKay HM (2008) Improving Cross-sector Policy Integration and Cooperation in Support of Freshwater Conservation, Conservation and Policy, 22(6): 1382-1387, DOI: 10.1111/j.1523-1739.2008.01080.x

Ruth JM, Petit DR, Sauer JR, Samuel MD, Johnson FA, Fornwall MD, Korschgen CE, Bennett JP (2003) Science for Avian Conservation: Priorities for the New Millennium, The Auk, 120(1):204-211, DOI: http://dx.doi.org/10.1642/00048038(2003)120[0204:SFACPF]2.0.CO;2

Wells R, Weiner BJ (2007) Adapting a Dynamic Model of Interorganizational Cooperation to the Health Care Sector, Medical Care Research and Review, 64: 518-543 